\title{
NORMATIVIZACIÓN DEL ENGAÑO Y NIVEL DE PROTECCIÓN DE LA VÍCTIMA EN LA ESTAFA: LO QUE DICE Y NO DICE LA DOGMÁTICA*
}

\author{
THE NORMATIVE CONSTRUCTION OF THE DECEPTION \\ ELEMENT IN THE OFFENCE OF FRAUD AND THE STANDARDS OF \\ VICTIM'S PROTECTION: WHAT DOES CRIMINAL LAW DOCTRINE \\ SAY AND WHAT DOESN'T?
}

\section{HÉCTOR HERNÁNDEZ BASUALTO**}

\begin{abstract}
RESUMEN: El artículo se hace cargo críticamente de una asunción implícita en la recepción de los impulsos normativistas en la dogmática de la estafa en el ámbito iberoamericano, consistente en que una dogmática normativista confirmaría necesariamente la interpretación restrictiva del engaño típico de la estafa que tradicionalmente ha imperado en dicho ámbito. A través del análisis de los principales argumentos de la tesis restrictiva, el autor procura demostrar que ni la tendencia normativista en general ni los específicos desarrollos de esa tendencia en materia de estafa sirven de apoyo para dicha tesis, y que, más bien al contrario, son fuente de importantes objeciones en su contra.
\end{abstract}

Palabras clave: estafa, engaño, normativización.

ABSTRACT: The paper critically focuses on an implicit assumption made by Hispano-American criminal law doctrine concerning the current general tendency to construct in a normative way ("normativization") the fraud offence. According to this assumption, the tendency to normative constructions in criminal law theory necessarily confirms the so far widely accepted restrictive interpretation of the deception element in the offence of fraud. Through an analysis of the premises for such a restrictive interpretation, the author aims to prove that nor the tendency to normative constructions, in general, neither the specific development of that tendency in the field of the fraud offence, in particular, support that conclusion; on the contrary, from these tendencies emerge important counterarguments against it.

Key words: fraud, deception, normative construction ("normativization”).

\footnotetext{
* Este trabajo se inscribe en el proyecto de investigación Fondecyt 1085159, "Cuestiones fundamentales de la dogmática de la estafa en el derecho penal chileno", ejecutado por el autor en la Universidad Diego Portales en calidad de investigador responsable. El texto se benefició de una estadía de investigación en mayo de 2009 en el Instituto de Criminología y Derecho Penal Económico de la Universidad de Freiburg. Gracias a la hospitalidad de su director, el Prof. Roland Hefendehl, y en la Universidad de Barcelona, gracias a la hospitalidad del Prof. José-Ignacio Gallego Soler. Además, fue presentado y discutido en sendos seminarios en el Instituto Max-Planck de Derecho Penal Extranjero e Internacional (Freiburg), en la Universidad de Bonn, en la Fundación Ortega y Gasset (Madrid), en la Universidad Pompeu Fabra y en la Universidad de Barcelona. El autor agradece muy sinceramente, por su hospitalidad y por la espléndida discusión, junto a los dos primeros nombrados, a los Profesores Urs Kindhäuser (Bonn), Enrique Bacigalupo (Madrid) y Jesús María Silva Sánchez (Barcelona), así como al Dr. Pablo Galain (Freiburg).

** Licenciado en Derecho por la Pontificia Universidad Católica de Chile, legum magister y Doctor en Derecho por la Universidad de Freiburg, Profesor de Derecho Penal de la Universidad Diego Portales. Correo electrónico: hector.hernandez@udp.cl
} 


\section{CONTEXTO Y PROPÓSITOS}

La delimitación del tipo penal de estafa suele discurrir sobre la cuestión en torno a cuánta protección merece la víctima de un engaño con consecuencias patrimonialmente perjudiciales. Si bien esta pregunta se puede plantear y efectivamente se plantea a propósito de todos los elementos de la estafa ${ }^{1}$, lo cierto es que la discusión a su respecto se ha concentrado principalmente en la definición del engaño típico, contexto en el cual lo relevante es sobre todo si la víctima crédula, torpe o negligente merece o no la protección que el tipo está llamado a proveer.

Concretamente, la pregunta en sede de engaño típico es si una inveracidad simple y aun burda satisface las exigencias del concepto o si, por el contrario, este requiere una inveracidad con cierto grado de calificación en términos de complejidad, gravedad o idoneidad general para inducir a error. Como se sabe, las respuestas al respecto son muy diferentes en los distintos ordenamientos jurídicos. Así, por ejemplo, mientras en Alemania $^{2}$, en Inglaterra o en los Estados Unidos $^{3}$ no se le imponen mayores exigencias al engaño típico -al menos no desde esta perspectiva- los países tributarios de la tradición iniciada por el Code pénal de 1810 suelen exigir notas más o menos relevantes de calificación ${ }^{4}$. Destaca en este sentido la situación en España, donde la exigencia de calificación incluso parece confirmada expresamente desde 1983 por la referencia legal a un "engaño bastante" para inducir a error a otro". Esto es también lo que, sin perjuicio de importantes matices entre sus representantes, sostiene la opinión ampliamente dominante en Chile ${ }^{6}$.

1 Piénsese por ejemplo en lo que está implicado en la disputa entre un concepto económico (con o sin apellidos) y uno personal de patrimonio, al respecto HeRNÁNDEZ (2008 b) pp. 195 y ss.

2 Tiedemann (2000) Vor $\$ 263$ margs. 36 y ss.

3 Si bien en términos más bien tácitos, por ejemplo para Inglaterra SiMESTER y SULLIVAN (2003) p. 516; para los Estados Unidos LAFAVE y SCOTT (1986) \$8.7 (p. 743), en ambos casos respecto de la atipicidad de las "exageraciones" en las ofertas comerciales, lo que bien visto, sin embargo, se refiere a informaciones irrelevantes para la transacción. Véanse al respecto los comentarios al influyente $\$ 223.3$ del Model Penal Code. Una documentada síntesis de la situación en ambos países desde la perspectiva de la dogmática continental en WAGEMANN (2005) pp. 423 y ss.

${ }^{4}$ En el derecho francés la exigencia de manoeuvres frauduleuses (art. 313-1 CP) se entiende como exigencia de engaño calificado y exclusión de la simple mentira (simple mensonge) del ámbito típico, al respecto MAYAud (2003) Art. 313-1 Nos 38 y ss.; LARGUier y CONTE (2004) pp. 106 y ss.; WalTER (1999) pp. 80 y ss. Algo similar rige para el derecho suizo con su exigencia de actuar fraudulento (arglistiges Handeln) en el $\$ 146$ StGB, al respecto TIEDEMANN (2000) Vor $\$ 263$ marg. 52. A primera vista la situación es distinta en el derecho italiano desde que el Código de 1930 (Art. 640) abandonara la exigencia expresa de idoneidad del engaño (artifici o raggiri atti a ingannare) contenida en el Código Zanardelli de 1889, al respecto DE FRANCESCO y ZANCHETTI (1999) Art. 640 marg. 8; véase también DOLCINI y MARINUCCI (2006) Art. 640 margs. 7 y ss., sin perjuicio de lo cual un sector relevante de la doctrina aboga ya de lege lata por una restricción del engaño relevante, así ya PEDRAZZI (1955) pp. 234 y ss.

5 BAJO FERNÁNDEZ (2004) pp. 32 y ss.

${ }^{6}$ ETCHEberry (1998) pp. 393 y ss., 407, 411 y s.; GARRIDO (2000) pp. 323 y ss.; Yubero (1993) pp. 103 y ss.; BULLEMORE y MACKINNON (2005) pp. 126 y ss.; en principio también, aunque ambiguo, LABATUT (1983) pp. 225 y ss. Mucho menos exigentes, pero también admitiendo un umbral general mínimo de idoneidad y magnitud bajo el cual el engaño no sería típico MERA (1986) pp. 39 y ss., 111 y ss.; PiÑA (2004) pp. 46 y ss.; FERnÁNDEZ (2005) pp. 186 y ss.; MAYER (2008) pp. 381 y ss. De otra opinión solo POLITOFF et al. (2005) pp. 430 y s.; y HeRnÁNDEZ (2003) pp. 161 y ss. 
Estas distintas soluciones -que curiosamente se dan a partir de textos legales las más de las veces similares y bastante neutrales al respecto- parecen responder simplemente a distintos desarrollos políticos, sociales y culturales que han dejado su huella en la interpretación del tipo penal ${ }^{7}$, de modo que pueden ser compartidas o rechazadas en esos mismos términos.

Este trabajo no versa, sin embargo, sobre esa discusión. De lo que aquí se trata es de la pregunta más específica en torno a si la normativización de la dogmática de la estafa tiene algo que decir en ella y, en caso afirmativo, en qué sentido y con qué consecuencias. El interés por este aspecto no es en absoluto casual, pues se hace cargo críticamente de una tendencia perceptible en parte de la literatura reciente en orden a atribuirle a la normativización consecuencias relevantes para la mencionada discusión política.

Como se sabe, la creciente normativización que la dogmática penal en general ha sufrido en las últimas décadas, especialmente a través de las diversas variantes del debate en torno a la imputación objetiva, ha terminado por alcanzar todas las parcelas del ordenamiento punitivo. En el caso de la estafa lo que en rigor llama la atención no es tanto el desembarco del normativismo en sus playas, sino más bien el relativo rezago del mismo. Como ha puesto de relieve Silva Sánchez, es precisamente en el campo de los delitos referidos a la actividad económica, esto es, el de los delitos patrimoniales y económicos donde se dan las condiciones propicias para el desarrollo normativista:

"Son varias las razones por las que parece posible afirmar que precisamente este ámbito puede constituir uno de los más aptos para la normativización que propone la doctrina de la imputación objetiva. En primer lugar, el alejamiento de los 'delitos de sangre' permite obviar con mayor facilidad algunos de los obstáculos emocionales que el dogma causalista (y el complementario dogma subjetivista) oponen, en el homicidio o las lesiones, a una mayor normativización. En segundo lugar, el conflicto entre esferas patrimoniales ('libertades' económicas) característico de estos delitos constituye, por su menor anclaje naturalístico, un espacio idóneo para la reflexión normativista sobre cuáles han de ser las fronteras entre las libertades jurídico-penalmente irrelevantes de los sujetos activos y las libertades jurídico-penalmente garantizadas de los sujetos pasivos. En donde los papeles de sujeto activo y sujeto pasivo se ven, por lo demás, constantemente intercambiados en las diversas interacciones económicas. En tercer lugar, buena parte de los delitos patrimoniales fraudulentos tienen lugar en contextos ya de por sí fuertemente normativizados por la existencia de regulaciones jurídicas extrapenales que definen con cierta precisión las respectivas esferas de competencia"8.

Pues bien, aquí se sostiene que esto es fundamentalmente correcto, pero se disiente de una pretensión implícita en la peculiar recepción que en el ámbito iberoamericano se ha hecho de los impulsos normativistas en materia de estafa, como es que el único 
punto de vista compatible con dicha normativización y, en general, con el actual estado del desarrollo dogmático sería precisamente la exigencia de un engaño calificado correspondiente a un alto nivel de merecimiento de protección de la víctima.

En efecto, aun cuando no siempre de modo explícito, el recurso a las distintas variantes de la doctrina de la imputación objetiva en materia de estafa ha servido nítidamente tanto en España como en algunos países sudamericanos, entre ellos Chile, como argumento adicional de justificación de la opinión restrictiva dominante en materia de engaño típico. Y debe reconocerse que, en la medida en que dicha doctrina tiende a fundar límites de la imputación jurídico-penal, la asociación parece a primera vista hasta natural, con la consecuencia de que los partidarios de una tesis minoritaria no deben enfrentarse ahora solo a las tradicionales razones políticas (y hasta idiosincráticas) en favor de un engaño calificado, sino que además deben defenderse del reproche de argumentar desde los extramuros del discurso dogmático aceptado.

A continuación se pretende demostrar que la opinión restrictiva dominante en España y en Chile no constituye en absoluto una consecuencia necesaria de la normativización de la dogmática de la estafa y que, más bien al contrario, esta puede ser una fuente importante de objeciones a aquella.

Antes de abordar esta tarea se impone una precisión conceptual. La consideración de la credulidad o diligencia de la víctima en rigor solo debería ser relevante en materia de error y no de engaño, puesto que se trata de factores que lógicamente ya no pueden incidir en la calificación de la conducta previa del agente, con la consecuencia -de la mayor importancia práctica- de que su valoración en un sentido restrictivo a lo más permitiría negar la consumación del delito, pero no la tipicidad y punibilidad de la conducta a título de delito frustrado 9 . La cuestión puede incidir en la calificación de la conducta engañosa -y en su eventual atipicidad y consecuente completa impunidad- solo si y en la medida en que la valoración de estos factores se generaliza y proyecta en términos abstractos en la definición del tipo de engaño que exclusivamente una víctima crédula, torpe o negligente se tomaría en serio. Pero entonces se trata de características y circunstancias propias del engaño típico, definidas previamente en términos generales y abstractos, y para cuya constatación en casos particulares la reacción de la víctima concreta - no así sus circunstancias- es del todo irrelevante ${ }^{10}$. Si bien no todas las contribuciones al debate observan esta precisión, en la medida en que asocian a la negligencia o excesiva credulidad de la víctima la total impunidad de la conducta, serán tratadas aquí sin distinciones como si efectivamente se refirieran a la definición del engaño típico en los términos explicitados.

\footnotetext{
${ }^{9}$ En nada modifica esta conclusión la postura que se mantenga en cuanto a la relevancia de la tentativa inidónea, en la medida en que se acepta que la idoneidad de la conducta debe evaluarse conforme a un criterio ex ante.

${ }^{10} \mathrm{Si}$ se considera, por ejemplo, que el comprador de un bien raíz que no verifica la inscripción del mismo a nombre del vendedor en el registro del Conservador de Bienes Raíces actúa negligentemente y no merece protección penal a través de la estafa, la proyección de ese juicio en el elemento engaño implica negarle en general el carácter de engaño típico a la aseveración de ser dueño no respaldada por una inscripción falsa de dominio o por algún otro elemento que ex ante considerado pueda justificar el error de un comprador, con total independencia de que luego el comprador concreto verifique o no la situación registral o sea más o menos diligente.
} 


\section{ENGAÑO CALIFICADO E IMPUTACIÓN OBJETIVA}

En buena medida la normativización de la dogmática de la estafa y en particular del engaño típico ha estado marcada por el intento de aplicar a su respecto la doctrina de la imputación objetiva en sus diversas variantes. Con esto se confirma la tendencia a resolver cuestiones interpretativas de la Parte especial con criterios de imputación propios de la Parte general, lo que en materia de estafa ha sido especialmente notorio, puesto que en esos criterios generales parecen cifrarse las esperanzas de superación de las dificultades interpretativas del tipo ${ }^{11}$. Concretamente, al menos en el ámbito iberoamericano, tales criterios se han empleado sobre todo para justificar y delinear la exigencia de un engaño calificado en la estafa.

A continuación se exponen críticamente los principales argumentos "de imputación objetiva" que se dan para excluir los engaños no calificados del ámbito de la tipicidad y se intenta refutarlos en los propios términos de la dogmática de Parte general.

\section{A) DÉfICIT DE ADECUACIÓN}

Los primeros intentos por vincular el tipo de estafa con la doctrina general de la imputación objetiva se valen de los criterios ya tradicionales de la llamada imputación objetiva del resultado (à la Roxin). En lo que concierne específicamente a la definición del engaño típico, estas aproximaciones se centran en la exigencia de creación de un riesgo prohibido, en este caso de un riesgo prohibido de error y ulterior disposición patrimonial perjudicial. Si se prescinde por ahora de la consideración de posibles ámbitos de riesgo permitido (al respecto infra b]) y solo se considera la creación de un riesgo en cuanto tal, como posibilidad relevante de resultado, algunos partidarios de la tesis restrictiva han sostenido que un engaño simple o burdo, por sus propias características, no podría superar el llamado juicio de adecuación o "pronóstico objetivo-posterior" propio del primer nivel de imputación, esto es, que desde una perspectiva ex ante y sobre la base de la experiencia común un observador imparcial y razonable no vería como posible que dicho engaño produjera un error. Se trataría en consecuencia de una conducta inidónea y, por lo mismo, atípica, sin necesidad de consideraciones normativas adicionales.

Un buen ejemplo de esto lo ofrece la contribución de Mercedes Pérez Manzano a las jornadas que la Universidad Autónoma de Madrid organizara en 1992 en honor de Klaus Tiedemann con motivo de su investidura como Doctor honoris causa ${ }^{12}$. Con expreso apoyo en Roxin, la autora analiza la adecuación del engaño en términos de creación de un riesgo típicamente relevante, contexto en el cual afirma que la mentira burda (de la que serían ejemplos la venta del Museo del Prado o la venta de supuestos relojes Omega o Rolex a un precio ínfimo) no crearía ningún riesgo prohibido en el

11 Así, paradigmáticamente, NAMER (2002) pp. 12, 48 y ss. y passim, sin contar con el inequívoco subtítulo: "El abordaje con criterios de la parte general de una problemática considerada clásicamente como de parte especial"; en Chile PIÑA (2004) pp. 43 y s.; FERNÁNDEZ (2005) pp. 186 y ss.

12 Pérez ManZano (1995) pp. 285 y ss. 
sentido del tipo, toda vez que desde una perspectiva ex ante, considerando las circunstancias conocidas o reconocibles, por regla generalísima no conseguiría engañar a un hombre medianamente diligente, sin perjuicio de la consideración excepcional de circunstancias extraordinarias (incapacidad, socialización exótica, etc.) que han sido conocidas por el autor en la forma de un "conocimiento especial"13. Si bien la autora se hace cargo especialmente de la diligencia de la víctima y en particular de sus supuestos deberes de autoprotección en un contexto posterior, a propósito de la realización del riesgo prohibido en la serie de resultados típicos de la estafa ${ }^{14}$, de todas maneras proyecta esa diligencia en el juicio sobre la creación del riesgo prohibido, en términos de que " $a$ mayor deber de diligencia de la víctima mayor despliegue de actividad engañosa requerido para afirmar la idoneidad del engaño" 15.

Estos resultados ciertamente coinciden con la mirada restrictiva de la estafa que es propia y característica de la tradición jurídica española, pero al mismo tiempo es notorio que no se fundan en la aplicación consistente del pronóstico objetivo-posterior con que debería verificarse la creación en cuanto tal de un riesgo prohibido, no al menos en el sentido que Roxin le asigna al mismo ${ }^{16}$, sino que en una sutil pero decisiva restricción del punto de vista relevante.

En efecto, cuando Pérez Manzano enjuicia la idoneidad del engaño no se pregunta por la aptitud de este para engañar en general a alguien, sino solo por su aptitud para engañar a un hombre "medianamente diligente" 17 , lo que confirma luego al proyectar sobre el engaño típico la diligencia y los supuestos deberes de protección de la víctima, con lo cual introduce una restricción que no es inmanente al método de la imputación objetiva del resultado. No se trata con esto de poner en duda que el pronóstico objetivoposterior se construye sobre la figura de un "observador razonable", sino simplemente de recordar que lo que ese observador razonable debe enjuiciar es si la conducta concreta permite fundar, con base en la experiencia común y en las circunstancias conocidas y cognoscibles, un pronóstico sobre el posible acaecimiento de un determinado resultado típico, y no de enjuiciar la mayor o menor razonabilidad del método ${ }^{18}$. En este caso, solo debe enjuiciar si el engaño en cuestión puede inducir a error a un grupo mínimamente relevante de personas, no si él mismo -verdadero símbolo de la razonabilidadcaería en él. Y cualquiera que conozca mínimamente la praxis en materia de estafa sabe

\footnotetext{
13 Pérez Manzano (1995) pp. 294 y ss. En el mismo sentido en Chile Fernández (2005) p. 187. Un importante antecedente en la literatura alemana, abogando por la causalidad adecuada en vez de la equivalencia de las condiciones en materia de estafa, NAUCKE (1974) pp. 109 y ss. (118 y s.).

14 PÉreZ ManZano (1995) pp. 305 y ss.

15 PÉREZ MANZANo (1995) p. 297 (énfasis en el original).

16 ROXIN (2006 a) \$ 11 margs. 40, 56 y ss.

17 PÉrez MANZANo (1995) p. 294.

18 Para expresarlo con un ejemplo, a diferencia de lo que ocurre con la técnica de clavar alfileres en un muñeco o de lanzar maldiciones, un observador razonable ciertamente puede, sobre la base de la experiencia común, formular un pronóstico jurídicamente relevante de muerte cuando a una persona se le administra una dosis pequeña de un veneno de mediana toxicidad o se le dispara con un revólver a una distancia de varios metros, aunque estos no sean los métodos más efectivos -ni, por lo mismo, los más razonablespara matar a alguien.
} 
que los llamados engaños burdos suelen tener unos niveles de éxito que no por sorprendentes dejan de configurar la experiencia común que se espera que el observador razonable incorpore en su pronóstico objetivo-posterior. Si realmente se trata de un engaño burdo su incidencia estadística en la producción de errores debería ser baja, pero difícilmente al punto de que pueda negársele relevancia en los términos "normales" de la imputación objetiva del resultado ${ }^{19}$.

Por lo mismo, autores que no comparten la posición restrictiva dominante pueden fundar la relevancia potencial del engaño burdo precisamente en los términos en general aceptados del juicio de adecuación ${ }^{20}$, en tanto que los partidarios de la tesis restrictiva que insisten en vincularla a los criterios de la imputación objetiva del resultado suelen concentrar sus esfuerzos no ya en negar la creación del riesgo en cuanto tal -lo que más bien terminan admitiendo ${ }^{21}$ - sino en justificar su carácter de "riesgo permitido".

\section{B) RIESGO PERMITIDO EN SENTIDO TRADICIONAL}

Aunque no se pudiera negar la adecuación de la conducta en términos de la creación de un riesgo de error, sí podría sostenerse -todavía en un esquema rigurosamente roxiniano- que ese riesgo se sitúa en el ámbito del riesgo permitido ${ }^{22}$. Así, por ejemplo, Pérez Manzano ha hecho presente la existencia de engaños socialmente tolerados en razón de la utilidad social de la actividad en que se insertan ${ }^{23}$.

Parece claro, sin embargo, que solo una licencia verbal permitiría equiparar la inveracidad con tendencia patrimonialmente perjudicial en el tráfico económico con los casos reconocidos de riesgo permitido en razón de su utilidad social. Es ciertamente posible que la publicidad y en general las ofertas económicas sean tan indispensables para la vida social como lo son el tráfico rodado o la industria farmacéutica, pero no se aprecia por qué habría de regir respecto de aquellas algo distinto de lo que rige para estas actividades, que solo están permitidas bajo la condición de respeto de regulaciones más o menos intensas que persiguen limitar los riesgos asociados al máximo todavía compatible con el desarrollo mismo de la actividad ${ }^{24}$. Así, por ejemplo, los límites de velocidad o los protocolos de prueba de medicamentos no pueden, en aras de la máxima seguridad, llegar al extremo de

19 Otra cosa puede regir solo si se restringe normativamente el punto de vista relevante ya para el juicio mismo de adecuación, como hace FERNÁNDEZ (2005) pp. 188 y s., a propósito del "grado de tendencia" exigido por dicho juicio, con lo cual, sin embargo, el autor parece abandonar el campo de la tradicional imputación objetiva del resultado y entrar al de la imputación objetiva de la conducta. Es sugestivo al respecto que la fusión entre juicio de adecuación y reconocimiento de riesgo permitido -o más exactamente: la prescindencia del primero por no ser normativamente relevante- sea una de las notas características de la imputación objetiva en Jakobs (JAKOBS [1991] 7/32 y ss.). Desde luego esto puede ser correcto, pero se ubica en otro nivel de argumentación (al respecto infra c]).

${ }^{20}$ Así, por ejemplo, en Chile, POLitoff et al. (2005) pp. 430 y s.

21 Valle Muñiz (1987) pp. 167 y s.; antes que él, tácitamente, Torío López (1982) pp. 886 y ss. Aparentemente también NAMER (2002) pp. 73 y ss., quien si bien distingue entre hipótesis de tentativa irreal o supersticiosa (que no crearían riesgo) e hipótesis de riesgo permitido, en definitiva solo da ejemplos de lo segundo (fundamentalmente de publicidad engañosa).

22 ROXIN (2006 a) $\$ 11$ margs. 65 y ss.

${ }^{23}$ Pérez ManZano (1995) pp. 298 y s.

${ }^{24}$ ROXIN (2006 a) $\$ 11$ marg. 67. 
hacer imposible un eficiente tráfico rodado o una oferta farmacéutica razonablemente oportuna. Pero sostener que no es posible desarrollar la actividad publicitaria o, en general, que no es posible sostener contactos económicos sin mentiras que provoquen perjuicios patrimoniales al resto parece sencillamente un exceso. Como se ve, el punto en discusión no es la utilidad social de la publicidad, sino solo la -apenas sostenible- utilidad social de la mentira con tendencia al perjuicio patrimonial en el tráfico económico.

Por cierto se puede hablar todavía de riesgo permitido en un sentido mucho más débil, de simple adecuación social, aproximación que tiene cierta tradición tanto en España $^{25}$ como entre nosotros gracias a las reflexiones de Jorge Mera ${ }^{26}$, incluso antes de la discusión sobre la imputación objetiva ${ }^{27}$. En este contexto, sin embargo, surge la duda de si la opinión restrictiva dominante realmente se limita a constatar la existencia efectiva de tal supuesta tolerancia o si, por el contrario, se esfuerza en imponerla, porque es notorio que mientras nadie en general ve un delito en la labor del peluquero o en tener que permanecer forzosamente en el autobús hasta que este llegue al paradero, la situación no parece ser la misma cuando se "tima" a alguien, aunque sea mediante un engaño supuestamente burdo. En todo caso, se trata de un ámbito muy difuso ${ }^{28}$, donde se echa de menos el fundamento vinculante de la tolerancia. No es de extrañar, por lo mismo, que los desarrollos más relevantes en la materia se estructuren sobre bases conceptuales bastante más precisas.

\section{C) ENGAÑO COMO INFRACCIÓN DE UN DEBER DE VERACIDAD}

Como se sabe, la doctrina de la imputación objetiva se ha focalizado en los últimos años en las notas de relevancia de la conducta típica, relegando a un segundo plano el tradicional interés por la conexión entre esta y el resultado típico en los delitos de resultado, en lo que se ha dado en llamar imputación objetiva de la conducta (à la Jakobs). En ese contexto la idea central es que existen distintas esferas de competencia en relación con los riesgos que el derecho pretende evitar y que la responsabilidad penal supone la infracción de deberes propios de la respectiva esfera de competencia.

En el ámbito específico de la estafa esta idea se ha expresado principalmente en la concepción del engaño como la infracción de un deber de veracidad por parte del autor o, correlativamente, como lesión de un derecho a la verdad que asiste a la víctima. Si se prescinde de la fortuna de la elección terminológica, que lamentablemente debe cargar el peso de reminiscencias históricas de fuerte carácter moralizante ${ }^{29}$, lo que esto implica

\footnotetext{
25 Torío lópez (1982) p. 887; VAlle MuÑIZ (1987) pp. 168 y ss., ambos con una referencia (terminológicamente impropia) al criterio del incremento del riesgo; la misma PÉREZ MANZANO (1995) pp. 298 y s. ${ }^{26}$ MERA (1986) pp. 112 y s. con nota 105, con expresa remisión a Welzel, en cuyas reflexiones respecto de la adecuación social (en especial en su formulación original: WELZEL, Hans: Studien zum System des Strafrechts, ZStW 58 [1939], 491 [517], citada según WelZEL [1975] pp. 120 y ss. [p. 142]) se tiende a reconocer actualmente un antecedente ineludible de la moderna teoría de la imputación objetiva, al respecto CANCIO MELIÁ (1993) p. 697 (en especial pp. 704 y ss.).

27 Recuérdese que la primera edición de su libro es de 1971.

28 PÉrez MANZANo (1995) p. 299.

${ }^{29}$ Un panorama del rol desempeñado por un supuesto "derecho a la verdad" en el desarrollo histórico del tipo penal de estafa en NAUCKE (1964) pp. 62 y ss., 92 y ss., 101 y ss.
} 
es que no toda mentira ni toda producción de error en otro constituye engaño típico, sino solo aquella que implica la infracción de un preciso deber de veracidad, que supone que el sujeto es competente y debe responder por la corrección de determinadas informaciones y por la evitación de errores en sujetos determinados. En otras palabras, en alguna medida el autor debe ser garante respecto de la víctima no solo en los casos de engaño por omisión sino en todas las hipótesis, lo que, además de suministrar una base dogmática común para todas las formas de engaño, implica una restricción no despreciable de los alcances del engaño típico ${ }^{30}$. Este último aspecto sugiere una coincidencia importante con la tesis restrictiva dominante en el ámbito iberoamericano, de modo que no era de extrañar que se quisiera ver en la concepción del engaño como infracción de un deber de veracidad una confirmación - normativamente más elaborada- de dicha tesis restrictiva.

La principal recepción de esta concepción en la literatura española se debe a Nuria Pastor Muñoz. Con apoyo en autores como Kindhäuser y Pawlik la autora asume como punto de partida que el engaño típico solo puede consistir en la infracción de un deber de veracidad del autor en favor de la víctima ${ }^{31}$, deberes que deberían extraerse de la estructura normativa del mercado ${ }^{32}$. A partir de ahí Pastor Muñoz desarrolla un sistema de deberes de veracidad de la mano del criterio de la accesibilidad normativa a la información, que conjuga el dato fáctico de la posibilidad de acceso con la consideración de la posición económica del sujeto en la relación y la exigibilidad -en términos de racionalidad económica- de procurarse la información susceptible de ser obtenida ${ }^{33}$. La víctima no tendrá ningún derecho a información veraz cuando dicha información ha sido normativamente accesible para ella, a menos que en el caso concreto se haya producido una redefinición de los deberes generales originales en virtud de la asunción de más riesgos de error por parte del autor (esto es, de más deberes de veracidad) o en virtud de que este haya puesto una barrera que impida el acceso de la víctima a la información (bloqueo) ${ }^{34}$.

En concreto será en principio tarea del destinatario de la información -a reserva de una posible redefinición de los deberes en juego- verificar su corrección en todo lo concerniente a sus propias circunstancias económicas y jurídicas ${ }^{35}$, así como en lo referido a las condiciones generales del mercado y a los aspectos jurídicos y económicos de la relación, salvo en casos excepcionales en que no tenga accesibilidad normativa a dicha

\footnotetext{
${ }^{30} \mathrm{Al}$ margen de importantes matices, adscriben en Alemania a esta concepción KINDHÄUSER (1991) p. 398 y passim; KINDHÄUSER (1997) pp. 354 y s.; KINDHÄUSER (2005) \$ 263 margs. 64 y ss.; PAWLIK (1999) pp. 148 y ss.; FRISCH (2008) pp. 738 y ss.; en buena medida ya FRISCH (2007) pp. 129 y s.; en lo fundamental, no obstante la autocalificación como "tesis intermedia", también VOGEL (2003) pp. 318 y ss., 322 y ss.; como antecedentes relevantes se cuentan JAKOBS (1986) pp. 808 y s.; y TIMPE (1989) pp. 136 y ss.

31 Pastor Muñoz (2004) pp. 133 y ss., 154 y ss., 217 y ss. Véase también: PASTOR MuÑoz (2003 a) pp. 453 y ss.; PAstor Muñoz (2003 b) pp. 67 y ss. En Chile, si bien con importantes diferencias, PIÑA (2004) pp. 48 y ss.; puntualmente también MAYER (2008) p. 392.

32 PASTOR MuÑoz (2004) pp. 212 y ss.

33 PASTOR MuÑoz (2004) pp. 224 y ss.

34 PASTOR MuÑoz (2004) pp. 231 y ss.

35 PASTOR MuÑoz (2004) p. 238.
} 
información, ya porque el acceso está restringido a la contraparte, ya porque tiene solo accesibilidad formal, pero le faltan los conocimientos para comprender la información ${ }^{36}$. Ahora bien, respecto de las circunstancias propias del potencial autor, contra lo que pudiera esperarse, la distribución del riesgo (y de los deberes) es fundamentalmente la misma, pues también depende de la accesibilidad normativa de la víctima:

"En este ámbito, en primer lugar, el autor tiene el deber de informar a la víctima sobre las informaciones normativamente inaccesibles para esta última. En segundo lugar, la omisión por el autor de informaciones normativamente accesibles a la víctima es un comportamiento permitido. En tercer lugar, la víctima no debe, en principio, confiar en afirmaciones del autor sobre informaciones que le incumbe a ella averiguar; por ejemplo, si el solicitante de un crédito comunica a la entidad bancaria que el inmueble que ofrece como garantía está libre de gravámenes, la entidad de crédito no debe confiar en tales afirmaciones porque le incumbe a ella averiguar la información en cuestión" 37 .

Respecto de qué puede considerarse todavía normativamente accesible dependerá, como se ha dicho, tanto de la posición económica del sujeto, como de qué tan proporcionado o desproporcionado parezca el esfuerzo por acceder a la información en atención a factores como la categoría de víctima ( $v$. gr. un consumidor o un banco) o la importancia del negocio, entre otros, con lo que el criterio de la accesibilidad coincide nítidamente con la idea de exigibilidad de dicho esfuerzo ${ }^{38}$. En otras palabras: accesibilidad es exigibilidad a la víctima.

De este modo Pastor Muñoz llega a resultados ampliamente coincidentes con los de la tesis restrictiva dominante en su país, al mismo tiempo que, sin embargo, se distancia de un modo abismante de aquellos a que arriban en Alemania los partidarios del engaño como infracción de un deber de veracidad y que, no obstante, le han servido como punto de partida.

En efecto, se aprecian enormes diferencias en primer lugar con Kindhäuser, quien, como se sabe, fue el primero que en la moderna discusión sobre la estafa consideró el engaño como infracción de un deber de veracidad. Para este autor el engaño supone por el lado de la víctima la existencia de una legitima pretensión a (o legítima expectativa de) información veraz ${ }^{39}$. Si se pregunta ahora, sin embargo, de dónde habría de derivarse una tal pretensión y cuál sería su alcance, se puede ver con nitidez que la propuesta conduce más bien a precisiones conceptuales que a restricciones dramáticas del tipo.

Según Kindhäuser, en la medida en que no existan deberes especiales de información o esclarecimiento, la obligación de expresar la verdad solo se desprende de la pretensión para si de una confianza especial, consistente en que "aquél que pretende que

\footnotetext{
36 PASTOR MUÑOZ (2004) pp. 241 y s.

37 PASTOR MuÑoz (2004) pp. 239 y s.

38 Si bien la autora elude en general la referencia a la exigibilidad, dicho criterio es una constante innegable en sus reflexiones. Así, por ejemplo, PASTOR MUÑOZ (2004) p. 237, 239, 240.

39 KINDHÄUSER (2005) \$263 margs. 90, 93.
} 
otro se involucre con él en una relación con riesgos para sus propios bienes no puede [no tiene derecho a] comportarse contradictoriamente sin una razón plausible" 40 . En concreto esto significa que el autor potencial debe decir la verdad respecto de los hechos en cuestión. Cuando por el contrario declara algo falso, queda obligado a corregir la información defectuosa, como ocurre por lo demás en general en los casos de injeren$\mathrm{cia}^{41}$. Dicho con un ejemplo: quien le ofrece a otro en venta una cosa pretende para sí la confianza en cuanto a que está facultado para disponer de la misma. Pues solo bajo esa premisa tiene sentido aceptar la oferta y asumir la obligación en favor del vendedor de pagar el precio de compraventa ${ }^{42}$. Posibles restricciones del engaño típico de acuerdo con este modelo surgen solo ahí donde el autor se ha expresado sin pretender para sí una confianza especial de parte de la víctima, como por ejemplo cuando el engañado no es el destinatario de la información defectuosa, sino simplemente la ha oído por casualidad ${ }^{43}$.

También en comparación con Pawlik los resultados prácticos son apenas comparables, a pesar de que este autor aboga decididamente por una distribución del riesgo de error fuertemente orientada a roles y con ello por una restricción importante del engaño típico en la estafa. En virtud de la necesaria adaptación del derecho penal a las condiciones generales de cooperación económica en sociedades funcionalmente diferenciadas, para la valoración jurídico-penal también deberían ser decisivas la anonimización y estandarización de las relaciones económicas interpersonales que caracterizan a dichas sociedades. De esto debería desprenderse que para la dogmática de la estafa en lo fundamental solo deberían ser relevantes las relaciones informativas típicas conforme a roles y las competencias vinculadas a ellas ${ }^{44}$.

Si se consideran ahora los casos que Pawlik denomina de competencia preferente de la víctima, se puede comprobar que estos se limitan al ámbito de las propias circunstancias (administración de caja y de contabilidad de propia responsabilidad, control sobre la realización de las propias necesidades y deseos ${ }^{45}$ ) y del pronóstico general de riesgos económicos ${ }^{46}$. En relación, en cambio, con los requisitos positivos de la competencia del autor, basta con la existencia de una relación de promesa relevante para la estafa, esto es, de una situación en la que la conducta del autor se pueda interpretar como una autovinculación jurídica (asunción de una garantía de verdad) en el sentido de que el autor aclara que está dispuesto a responder por la corrección de su información, de modo que su contraparte comunicativa puede conectar a ella medidas de administración patrimonial ${ }^{47}$. Esta exigencia no tendría, sin embargo, nada de extraordinario, ya que como principio rige que el autor tiene que garantizar el uso correcto de los signos semánticos y con ello el contenido significativo de los mismos ${ }^{48}$.

\footnotetext{
40 KINDHÄUSER (2005) \$ 263 marg. 95.

41 KINDHÄUSER (2005) \$ 263 marg. 95.

42 KINDHÄUSER (2005) \$ 263 marg. 95.

43 KINDHÄUSER (2005) \$ 263 marg. 97.

44 PAWLIK (1999) pp. 148 y ss.

45 PAWLIK (1999) pp. 157 y s.

46 PAWLIK (1999) pp. 152 y ss.

47 PAWLIK (1999) p. 142 (162).

48 PAWLIK (1999) pp. 164 (177 y ss.).
} 
Como se puede ver, la diferencia fundamental entre el modelo de Pastor Muñoz y el de los autores alemanes citados radica en que aquel asume como regla y punto de partida la responsabilidad preferente de la víctima, que solo conoce excepciones cuando no se le puede exigir más, en tanto que este reparte competencias neutral e igualitariamente en función de roles. La expresión más nítida de esto se encuentra en el tratamiento de la llamada autovinculación del autor como fuente de deber de veracidad más allá del ámbito del llamado engaño por omisión. Mientras que para Kindhäuser y Pawlik basta, como se ha visto, con la actuación en el mercado con la pretensión -totalmente ordinaria- de que otros conecten sus disposiciones patrimoniales a la información que uno entrega a través de los signos aceptados para ello ${ }^{49}$, Pastor $\mathrm{Mu}$ ñoz entiende que se trata de algo excepcional, de una "redefinición de los deberes iniciales de veracidad" por la vía de una "asunción de mayores deberes de veracidad", de modo que, consecuentemente, exige el cumplimiento de una serie de requisitos nada de ordinarios ${ }^{50}$.

La sola existencia de resultados tan discrepantes debería bastar para demostrar que la concepción del engaño como infracción de un deber de veracidad no implica necesariamente una restricción del tipo, al menos no en los términos defendidos por la tesis dominante en nuestro medio ${ }^{51}$. Más bien al contrario, debería dejar en evidencia la necesidad de justificar especialmente la asunción como punto de partida de la competencia preferente de la víctima entendida como punto de partida no solo respecto de cierto tipo de informaciones (punto en el cual están plenamente de acuerdo los autores alemanes citados), sino que respecto de todo tipo de informaciones, lo que, como se ha visto, no es en absoluto inmanente a esta concepción del engaño típico.

\section{D) DEBERES DE AUTOPROTECCIÓN A PARTIR DEL CARÁCTER RELACIONAL DE LA ESTAFA}

Una imputación preferente del error al ámbito de competencia de la víctima como regla general, independiente del tipo de información de que se trate, podría justificarse mediante el reconocimiento de la existencia de supuestos "deberes de autoprotección" que pesan sobre la víctima de la estafa, construcción que goza de gran predicamento en el derecho español ${ }^{52}$.

Los propios partidarios de los deberes de autoprotección de la víctima reconocen que se trata de una denominación poco adecuada - pues no se aprecia cómo podría justificarse la existencia de genuinos "deberes" de la víctima del delito- y que en rigor simplemente se trata de la consideración del comportamiento de la víctima en la valoración jurídico-penal de la conducta del autor, con efectos de atenuación e incluso, bajo ciertos

\footnotetext{
${ }^{49}$ KINDHÄUSER (2005) \$263 marg. 95; PAWLIK (1999) p. 142 (162).

50 PASTOR MuÑoz (2004) pp. 233 y ss.

51 Sobre los verdaderos efectos restrictivos de la normativización infra 4.

52 En la literatura reciente, entre otros, GÓMEZ Benítez (1985) p. 339; Pérez MANZANo (1995) pp. 305 y ss.; Choclán Montalvo (1999) p. 59; Choclán Montalvo (2000) pp. 108 y ss.; Bajo Fernández (2004) p. 39; Gallego SOler (2005) p. 529; GAllego SOler (2008) pp. 224, 235 y ss.; ARrOYO DE LAS HERAS (2005) pp. 29 y s.
} 
supuestos, de exención de responsabilidad penal de este último ${ }^{53}$. Como fuera, más allá del aspecto terminológico, lo realmente relevante es por qué el comportamiento de la víctima tendría que tener estas consecuencias en materia de estafa, en circunstancias que en general no las tiene respecto de otros delitos, particularmente respecto de otros delitos contra la propiedad o el patrimonio, como el hurto o la apropiación indebida ${ }^{54}$.

La respuesta estándar se centra en el reconocido carácter relacional de la estafa o, más específicamente, en su calidad de delito de "autolesión"55. Porque, en efecto, constituye una nota característica de la estafa el que para esta, a diferencia de lo que ocurre con el hurto o con cualquier otro delito de "heterolesión", una contribución de la víctima a la realización del tipo en la forma de un acto de disposición patrimonial perjudicial es necesaria, constitutiva, y no meramente contingente. Cabe preguntarse ahora, sin embargo, si de esta característica deben seguirse por fuerza exigencias especiales para el merecimiento de protección de la víctima, con la consecuente restricción de los alcances de la estafa. Y esto parece haber sido más postulado que demostrado.

Desde luego la afirmación no parece respaldada -sino más bien todo lo contrariopor los parámetros que aplica la dogmática penal general a casos en que, como ocurre precisamente en la estafa, se instrumentaliza a una persona para que produzca un resultado típico. Las instituciones de Parte general que exhiben un paralelismo estructural evidente con la "autolesión" propia de la estafa son fundamentalmente dos: la autoría mediata en virtud de engaño cuando el instrumento es la propia víctima (a lo que se puede agregar la obtención engañosa del consentimiento de la víctima) y el llamado principio de autorresponsabilidad de la víctima.

Respecto de lo primero, no es difícil reconocer en la estafa la estructura de la autoría mediata como forma de "dominio de la voluntad en virtud de error" 56 . Ocurre, sin embargo, que en materia de autoría mediata al engaño en virtud del cual se considera que el hecho es obra del hombre de atrás y no del instrumento no se le imponen mayores exigencias de idoneidad, como tampoco se le imponen al instrumento exigencias especiales para su liberación de responsabilidad en perjuicio del hombre de atrás, al punto que se afirma la autoría mediata incluso en casos de imprudencia consciente de aquel ${ }^{57}$. En esa medida, la concepción bastante extendida de la estafa como una hipótesis especialmente tipificada de

\footnotetext{
53 Así Gallego Soler (2005) pp. 529 y s. con nota 1; Cancio Meliá (1998) pp. 301 y s.

54 Por solo mencionar delitos cuyo objeto de protección debería hacerlos inmunes al posible argumento del carácter especialmente fragmentario de la protección penal de los intereses patrimoniales, que tal vez podría servir para justificar desde esta perspectiva un régimen diferente al que rige para la protección de bienes jurídicos personalísimos como la vida o la integridad corporal. Plantea las mismas dudas en España -si bien muy aisladamente- NAVARRO CARDOSO (1998) pp. 178 y ss.

55 Gallego Soler (2005) p. 557 con nota 93; Silva SÁnChez (1999) pp. 99 y s.: "Dado que la estafa es un 'delito de relación', no habrá sanción cuando la inveracidad habría podido ser descubierta sin especiales dificultades por el sujeto pasivo: así [...] cuando los deberes de diligencia del sujeto pasivo, derivados de la posición ocupada por este en el tráfico, le exigían -lo que además era posible- disipar la apariencia de veracidad y salir, con ello, de su error" (énfasis en el original).

56 La terminología es la impuesta por Roxin (2006 b) pp. 170 y ss.

57 RoXIN (2003) \$ 25 marg. 65 (más matizado aunque de todos modos coincidente en RoXIN [2006 b] pp. 180 y ss.), lo que hace extensivo expresamente a casos de producción engañosa de una autolesión (marg. 70).
} 
autoría mediata -también en parte en la literatura española ${ }^{58}$ - debería conducir precisa y consecuentemente a negar ese tipo de exigencias para el engaño típico y en caso alguno a su respaldo. La conclusión la extrae con toda nitidez y consecuencia Kindhäuser, precisamente uno de los autores que con mayor énfasis ha afirmado el carácter de la estafa como tipificación especial de una forma de autoría mediata ${ }^{59}$, cuando señala que no existe ninguna razón para abandonar el principio conforme al cual la negligencia del hombre de adelante que da lugar a su desconocimiento de la situación no excluye la responsabilidad del hombre de atrás en el sentido de la autoría mediata ${ }^{60}$.

Asimismo, es opinión ampliamente dominante que en el caso del consentimiento obtenido mediante engaño de la víctima se está en presencia de un consentimiento viciado sin efecto justificante ${ }^{61}$, de modo que las consecuencias del acto recaen íntegramente sobre el autor y no sobre la víctima. En lo que aquí interesa, tampoco en esta materia se le imponen mayores exigencias ni al engaño ni al comportamiento de la víctima para los efectos de tener por viciado el consentimiento.

En lo que concierne al principio de autorresponsabilidad, mientras la dimensión negativa del mismo implica que cada uno es responsable solo de sus propios actos y no de los actos de terceros ${ }^{62}$, su dimensión positiva señala que en principio es uno $-y$ no el resto- el único responsable de sus propios actos. A partir de esta premisa fundamental, en casos en que la víctima ha contribuido conjuntamente con un tercero a la puesta en peligro del bien jurídico en cuestión, se ha venido discutiendo intensamente si y en qué medida dicha contribución, esa "autolesión” o "autopuesta en peligro", puede eximir de responsabilidad al tercero ${ }^{63}$. Si a esto se le agrega la razonable intuición de que en un ordenamiento no paternalista es al titular de un bien jurídico a quien le corresponde la competencia primaria por su conservación ${ }^{64}$, la relación con una imputación preferente al ámbito de responsabilidad de la víctima en la estafa parece a primera vista evidente.

Y es así que, por ejemplo, Gallego Soler deriva del carácter relacional de la estafa la necesaria consideración de la contribución de la víctima a la consumación del delito en sede de imputación objetiva precisamente a los efectos de la operatividad del principio de autorresponsabilidad $^{65}$. Antes que él Pérez Manzano, también a partir de la idea de auto-

\footnotetext{
58 Choclán Montalvo (2000) pp. 151 y s.; con consecuencias restrictivas para el tipo SiLVA SÁNCHEZ (1999) p. 99; GALlego SOLER (2005) pp. 545 y s.

59 KINDHÄUSER (1997) pp. 339 y ss; KINDHÄUSER (2005) \$ 263 margs. 45 y ss.

${ }^{60}$ KINDHÄUSER (2005) $\$ 263$ marg. 52.

${ }^{61}$ En rigor la consecuencia se deriva del concepto mismo de consentimiento como acto libre de disposición sobre un bien jurídico propio, lo que desde luego no ocurre cuando, entre otros casos, este se obtiene mediante engaño. Se pronuncian expresa y específicamente sobre el punto en la literatura chilena NOVOA (1960) p. 415; COUSIÑO (1979) p. 525; NÁQUIRA (1998) p. 307.

${ }^{62} \mathrm{Al}$ punto que se suele hablar de principio de autorresponsabilidad "de los otros", al respecto, fundamentalmente, SCHUMANN (1986) pp. 6 y ss. y passim.

${ }^{63}$ ROXIN (1976) pp. 183 y ss.; FrisCH (1992) pp. 1 y ss. , 62 y ss.; CANCIO Meliá (1998) passim, con amplias referencias.

64 CANCIO MELIÁ (1998) p. 278.

65 Gallego Soler (2005) pp. 543 y s., "de tal manera que se es muy exigente con quien tiene medidas de autoprotección y no las utiliza” (p. 545), con referencias adicionales a la doctrina de la probibición de regreso.
} 
rresponsabilidad como expresión de autonomía ${ }^{66}$, ha sostenido la imputación del error al ámbito de responsabilidad de la víctima cuando esta no emplea los medios de autoprotección disponibles y exigibles ${ }^{67}$. Entre nosotros han sostenido la restricción del engaño típico a partir del principio de autorresponsabilidad Piña ${ }^{68}$ y, más recientemente, Mayer ${ }^{69}$.

Bien visto, sin embargo, se puede apreciar que ninguno de los modelos dogmáticos desarrollados en relación con la contribución de la víctima a la realización típica permite sostener las especiales exigencias que en materia de estafa se quieren imponer al engaño típico. En efecto, a pesar de los muchos matices con que se aborda la situación de la víctima que no actúa con pleno conocimiento de la peligrosidad de su conducta, al menos parece existir consenso en torno a que su competencia primaria decae precisamente ahí donde esta actúa como víctima de un engaño, engaño al cual no se le imponen mayores exigencias ${ }^{70}$.

En rigor, la argumentación con el principio de autorresponsabilidad en la estafa pasa por alto ni más ni menos que, por definición, una víctima engañada respecto de un aspecto relevante de su conducta -que es precisamente lo que ocurre con la víctima de la estafa- no actúa de modo autorresponsable. En ese escenario, lo que en definitiva pretende el argumento no es fundar en el principio de autorresponsabilidad una restricción del engaño típico, sino todo lo contrario, esto es, fundar en dicha restricción -cuya fundamentación sigue pendiente- una alteración puntual de los presupuestos generalmente aceptados de una conducta autorresponsable.

Un buen ejemplo de la clara discrepancia entre la tesis restrictiva en materia de estafa y el desarrollo general de criterios de imputación preferente a la víctima en base a su autorresponsabilidad lo ofrece la fórmula sintética propuesta por Cancio Meliá en su conocida monografía sobre conducta de la víctima e imputación objetiva, a saber:

"Cuando el titular de un bien jurídico ('víctima') emprende conjuntamente con otro ('autor') una actividad que puede producir una lesión de ese bien jurídico, la actividad generadora del riesgo debe ser imputada al ámbito de responsabilidad preferente de la víctima, en la medida en que

a) la actividad permanezca en el ámbito de lo organizado conjuntamente por autor y víctima,

b) la conducta de la víctima no haya sido instrumentalizada por el autor, por carecer esta de responsabilidad o de la base cognitiva necesarias para poder ser considerada (auto)responsable,

66 PÉreZ MANZANO (1995) p. 303.

67 Pérez MANZANO (1995) pp. 302 y ss., especialmente pp. 305 y s.

68 Piña (2004) pp. 50, 61 y s. No obstante el expreso apoyo en las tesis de Pastor Muñoz, el énfasis de Piña en el principio de autorresponsabilidad es mayor que el puesto por la autora española, para quien, bien visto, el principio solo es un punto de partida (la disposición patrimonial perjudicial es de responsabilidad de la víctima mientras no exista una razón normativa que permita traspasar esa responsabilidad al autor) pero no la justificación de los estrechos alcances que luego le asigna a los deberes de veracidad, que habrían de derivarse de la "estructura normativa del mercado" (cfr. PASTOR MUÑoz [2004] pp. 123, 224 y ss.). Al parecer Piña advierte que el solo punto de partida es insuficiente para sostener las conclusiones.

${ }^{69}$ MAYER (2008) pp. 384 y ss.

${ }^{70}$ Así, Frisch (1992) p. 64; ROXIN (2006 a) \$ 11 marg. 113. 
c) el autor no tenga un deber de protección específico frente a los bienes de la víctima"71.

Como es obvio el extremo relevante desde el punto de vista de la estafa es el de la letra b), esto es, que la víctima no haya sido instrumentalizada, específicamente por carecer de la base cognitiva para poder ser considerada autorresponsable. Se trata gruesamente de los casos de dominio por error o superioridad de conocimientos ${ }^{72}$. Del solo enunciado debería desprenderse, como ya se ha dicho, que el engaño por parte del autor impide la imputación a la víctima, lo que se ve confirmado luego por las explicaciones específicas del autor sobre ese punto, contexto en el cual solo se tematizan como problemáticas situaciones en que se puede dudar de la relevancia del objeto del error, así como la corrección o incorrección de aceptar una instrumentalización cada vez que el autor simplemente "aprehenda mejor el riesgo" que la víctima, pero en caso alguno se expresan exigencias especiales a la instrumentalización mediante engaño ${ }^{73}$. Las citas a este autor por parte de partidarios de la tesis restrictiva en materia de estafa manifiestamente no pueden servir de abono a dicha tesis ${ }^{74}$.

Podría objetarse ahora que las mencionadas categorías de la Parte general están desarrolladas fundamentalmente para delitos de heterolesión y no se pueden traspasar sin más al estudio de los delitos de autolesión como es el caso de la estafa ${ }^{75}$. Esto puede implicar dos cosas diferentes. O bien que se debe desarrollar un sistema separado de reglas de imputación para el conjunto de los delitos de autolesión, o bien que se trata en rigor de una cuestión exclusivamente atingente a la definición de las específicas reglas de comportamiento que configuran el tipo de estafa, esto es, de una cuestión exclusiva de Parte especial ${ }^{76}$. En todo caso, en la medida en que es precisamente la estafa el tipo penal en torno al cual parece haber girado el grueso de la discusión ${ }^{77}$, no es necesario

\footnotetext{
71 CANCIO MELIÁ (1998) p. 284.

72 Por su parte, el dominio por carencia de responsabilidad dice relación fundamentalmente con defectos de responsabilidad constitucionales y situacionales de la víctima, que guardan cierto paralelismo con las causas de exclusión de culpabilidad, al respecto CANCIO MELIÁ (1998) pp. 354 y ss.

73 Cancio Meliá (1998) pp. 363 y ss.

${ }^{74}$ Así, sin embargo, MAYER (2008) p. 385 (su cita corresponde a CANCIO MELIÁ [2003] pp. 279 y s.); en el caso de PIÑA (2004) p. 62, no hay cita expresa en este punto específico, pero el fraseo es inconfundible, aunque con una variación fundamental -e indispensable para sus fines- de autoría del autor chileno, quien exige que: "(b) La conducta de la víctima no haya sido instrumentalizada por el autor en aquellos casos en que la víctima carece de los antecedentes normativamente accesibles, que permiten afirmar su autorresponsabilidad" (énfasis agregado).

75 Cabe recordar, con todo, que es la propia opinión restrictiva dominante la que ha pretendido para sí el apoyo de la dogmática general construida fundamentalmente a partir de los delitos de heterolesión.

76 Sobre la distinción entre reglas de comportamiento y reglas de imputación y, con ello, entre los planos prescriptivo (propio de la Parte especial) y adscriptivo (propio de la Parte general), por todos, HRUSCHKA (2005) pp. 27 y ss.

77 Si se prescinde de delitos de heterolesión como los de violación de secretos (al respecto SCHÜNEMANN [1978] pp. 54 y ss.; SCHÜNEMANN [2000] Vor $\$ 201$ marg. 7; $\$ 201$ margs. 13, 24; $\$ 202$ margs. 2, 13; $\$ 202$ a margs. 14 y s.; $\$ 203$ margs. 16 y s.), apenas ha habido discusión sobre otros delitos de autolesión. Sobre intentos en materia de coacciones, amenazas y violación intimidatoria SILVA SÁNCHEZ (1989) pp. 645 y s.
} 
resolver aquí la disyuntiva. Baste con señalar que, efectivamente, se han levantado objeciones contra la aplicación de los mencionados criterios generales de imputación a la interpretación del engaño típico.

Así, por ejemplo, Frisch ha hecho presente que mientras lo que está en cuestión en la autoría mediata son las razones en virtud de las cuales el hombre de atrás debe responder por la ejecución por parte del instrumento de una conducta de antemano y en general inequivocamente prohibida, en la discusión en torno al engaño típico ${ }^{78}$ a título de estafa se trata precisamente de definir recién aquello que está prohibido, definición en la que influirían consideraciones que trascienden de los términos de la discusión propia de la autoría mediata y que tienen que ver con merecimiento y necesidad de protección de la víctima, con la libertad de acción del autor y con la delimitación de esferas de responsabilidad entre ambos ${ }^{79}$. Por su parte, en lo que concierne al paralelo con el consentimiento viciado, sostiene que la vinculación entre ambas instituciones solo resulta razonable en términos negativos, esto es, en cuanto a que por cierto debiera negarse el carácter típico a título de estafa de una disposición patrimonial que tratándose de un delito de heterolesión constituiría un caso de consentimiento justificante, pero que en términos positivos implicaría que solo se podría negar la tipicidad de la conducta a condición de que se cumplieran unas exigencias que en materia de estafa están completamente fuera de lugar, como por ejemplo, la de que el disponente no solo no haya sido engañado, sino que además tenga capacidad para consentir, etc. ${ }^{80}$.

Ahora bien, al margen de qué tan convincentes puedan ser estas observaciones ${ }^{81}$, lo cierto es que no mejoran en absoluto la situación de la tesis de la imputación preferente al ámbito de responsabilidad de la víctima. A lo más se puede decir que para la definición de la conducta típica de la estafa no rige necesariamente lo mismo que para las mencionadas categorías adscriptivas de la Parte general, pero de modo alguno se sigue de ello que puntualmente no pueda ser ese el caso $^{82}$, ni mucho menos que deba regir por fuerza algo totalmente diferente. Sin duda es esta última pretensión de la opinión restrictiva dominante en materia de estafa es la que está en deuda de razones.

\section{E) PRINCIPIO DE ULTIMA RATIO Y PONDERACIÓN DE INTERESES}

La idea central del principio de autorresponsabilidad, conforme a la cual la competencia primaria en la protección de un bien jurídico recae en el titular del mismo, conecta a la perfección con en el principio de ultima ratio y el carácter subsidiario del

78 En rigor las explicaciones de Frisch giran en torno al elemento "error", pero en la medida en que las conclusiones sobre este elemento se proyectan luego a la definición del engaño típico, son también aplicables a este último; del mismo modo lo ve WiTTig (2005) p. 369.

${ }^{79}$ FRISCH (1979) p. 652.

${ }^{80}$ FRISCH (1979) pp. 653 y s.

81 Entre nosotros debería compartirlas, por su aproximación general en materia de reglas de comportamiento, MAÑALICH (2006) pp. 69 y s.; en forma expresa contra la consideración de la estafa como autoría mediata especialmente tipificada, por inexacta, PIÑA (2004) p. 97 con nota 198.

82 MAÑALICH (2006) p. 70, concede que, al menos respecto de la estafa, la relevancia jurídico-penal del desplazamiento patrimonial sí parece poder explicarse como acto de disposición de la víctima en tanto instrumento. 
derecho penal, en la medida en que parece obvio que la protección penal solo viene prescrita ahí donde el sujeto ya no está en condiciones de protegerse por sí solo, pero no en el caso en que se haya relajado en la aplicación de sus posibilidades de autotutela primaria (vigilantibus iura sunt scripta) ${ }^{83}$. La preferencia de la autoprotección por sobre la tutela estatal en materia patrimonial estaría justificada porque en este ámbito existen especiales medios de autoprotección que hacen que la protección sea más fácil para el particular que para el Estado, así como porque la autorresponsabilidad del mismo es parte de su autonomía, la que se vería estorbada por la protección estatal ${ }^{84}$.

Esta es también la aproximación de la llamada corriente "victimodogmática", minoritaria en la literatura alemana y que, como es sabido, postula una restricción del tipo de estafa bastante coincidente con la opinión dominante en España y entre nosotros. Punto de partida de esta aproximación es una invocación general a los principios limitadores del ius puniendi, esto es, al principio de ultima ratio y al carácter subsidiario y accesorio del derecho penal, de donde se seguiría la máxima interpretativa conforme a la cual -por razones de necesidad de pena o, más específicamente, de necesidad de protección- solo debería subsumirse en el tipo penal una conducta que eludiera la autoprotección posible y exigible a la potencial víctima (llamado "principio victimológico") ${ }^{85}$.

Como se ha visto, sin embargo, esa supuesta evidencia desaparece cuando se considera el carácter instrumentalizador del engaño en la estafa. Por definición se trata de una víctima que si se lesiona a sí misma lo hace ignorante de su calidad de instrumento en manos de otro, lo que conforme a los parámetros generales y reconocidos de imputación debería bastar como razón normativa suficiente para desplazar la responsabilidad del titular del bien jurídico (que, consecuentemente, ya no está en condiciones de protegerse a sí mismo) al autor.

Si no obstante se sigue argumentando en este contexto con el principio de ultima ratio y el carácter subsidiario del derecho penal, solo puede serlo en un sentido diferente, no relacionado, en rigor, ni con el carácter relacional de la estafa ni con el principio de autorresponsabilidad, que, como se ha visto, no proveen de verdaderas razones para la tesis restrictiva dominante. Debe tratarse de razones en virtud de las cuales las víctimas de estafa merezcan menor protección que las víctimas de otros delitos.

Todo indica que las razones tienen que ver con la relativa "mala conciencia" que acompaña desde sus orígenes al tipo penal de estafa en la tradición continental como una forma de engaño "inmaterial”, esto es, emancipado de la falsificación y circulación

83 GALLEGO SOLER (2005) pp. 551 y ss., también con referencia al principio de unidad del ordenamiento jurídico.

84 Pérez Manzano (1995) p. 303; Gallego Soler (2005) p. 556.

85 Al margen de importantes diferencias SCHÜNEMANN (1978) pp. 54 y ss.; SCHÜNEMANN (1979) pp. 130

y s. (primera referencia expresa al "principio victimológico"); SCHÜNEMANN (1986) pp. 439 y ss.; SCHÜNEMANN (2002) pp. 61 y ss. Específicamente respecto de la estafa AMELUNG (1977) pp. 6 y ss.; HASSEMER (1981) pp. 72 y ss., 113 y ss., y passim (dependencia de la necesidad de protección de la propia contribución al grado de intensidad concreta del peligro); KURTH (1984) pp. 169 y ss.; ELLMER (1986) pp. 281 y ss. y passim (deber de desconfianza de la víctima); HilgENDORF (1998) pp. 103 y ss., 110 y s., 199 y ss.; a pesar de su crítica a la victimodogmática también HenNings (2002) pp. 169 y ss. Una temprana noticia (favorable) en la literatura española SiLVA SÁNCHEZ (1989) pp. 633 y ss. 
de cierto tipo de objetos, con las consiguientes dudas sobre la legitimación de la figura, las que no necesariamente desaparecen con la exigencia -hija del mismo contexto histórico- de perjuicio patrimonial ${ }^{86}$. A esto cabría agregar la circunstancia de que, al margen de su dañosidad potencialmente mucho mayor que la del hurto o el robo, la estafa no contradice radicalmente, como sí hacen estos últimos delitos, el régimen legal de atribución de derechos en materia de bienes, en la medida en que la disposición patrimonial, aunque viciada por definición, guarda al menos la apariencia de una transacción conforme a dicho régimen legal ${ }^{87}$.

En definitiva, parecen existir dudas respecto de la legitimidad y conveniencia del castigo de los engaños patrimonialmente perjudiciales, con lo cual se entra derechamente al terreno de la discusión político-criminal, terreno que, como se dijo, se ubica más allá de los propósitos de este trabajo. Con todo, cabe hacerse cargo siquiera brevemente de una forma de argumentación asociada al principio de ultima ratio y con gran influencia metodológica en una dogmática conscientemente normativista, como es la ponderación de intereses contrapuestos como herramienta para la delimitación de esferas de competencia ${ }^{88}$. Ya no se trata entonces solo de la víctima y de su merecimiento de protección penal conforme a los criterios generalmente reconocidos, sino también y en primera línea de la legitimidad de la intromisión en la esfera de derechos del autor.

Es en esto en lo que parece estar pensando Silva Sánchez al destacar el carácter liberal de lo que él llama el "modelo de la estafa" en el tratamiento de la inveracidad ${ }^{89}$, de tinte claramente restrictivo. Al menos es lo que parece desprenderse de sus reflexiones:

"En esta perspectiva, en efecto, se aprecia un determinado modo de articular las esferas individuales a propósito de las manifestaciones inveraces potencialmente lesivas, a saber, uno que parte del favorecimiento de la libertad de acción. En concreto, se sientan las bases para la configuración de espacios de inveracidad penalmente atípica (riesgo permitido), incluso aunque a la misma se asocie en términos 'causales' un perjuicio patrimonial de tercero. Dado que no hay un derecho subjetivo a la veracidad, no es la mera presencia de una inveracidad -ni siquiera con ánimo de perjudicar- la que implica la superación de la frontera de la intervención penal. La relevancia penal requiere, además, una organización de la propia esfera (la estafa es un delito de organización) de modo que la inveracidad trascienda a la misma y produzca una injerencia especialmente instrumentalizadora de la libertad del tercero. Si ello no es así, la manifestación inveraz se mueve en un espacio de libre organización permitida, que podemos adscribir genéricamente a la 'habilidad negocial'. Con lo anterior, en fin, se pretende dar razón del hecho

\footnotetext{
86 SCHLÜCHTER (1994) pp. 588 y s., y passim.

87 PAWLIK (1999) pp. 79 y ss., con abundantes referencias histórico-filosóficas y dogmáticas.

88 Desde luego la ponderación de intereses contrapuestos le corresponde en primera línea al legislador (específicamente respecto de la ineludible decisión legislativa de reprimir engaños patrimonialmente perjudiciales, HERNÁNDEZ [2003] p. 163), pero no puede negarse la función que también cumple, en sede interpretativa, en la concreción de los enunciados normativos.

89 SiLVA SÁNCHEZ (1999) p. 99.
} 
de que una cierta inveracidad -al igual que una cierta violencia física o moral- es inherente a la vida de relación social y no siempre punible" 90 .

La delimitación de esferas de responsabilidad aparece así como el resultado de una ponderación de los intereses que se enfrentan en la interacción económica, a saber, concretamente, por una parte la protección del patrimonio de la víctima y por la otra los intereses igualmente legítimos del potencial autor. Punto de partida de esta perspectiva es el reconocimiento de ciertas notas características -y totalmente legítimas- del modelo económico, como son, por una parte, que el lucro perseguido por los agentes económicos necesariamente se verifica a expensas del patrimonio de los otros y, por la otra, que la superioridad informativa de unos respecto de otros es un dato inherente a la estructura del mercado. Todo esto podría sugerir, en efecto, una restricción de los alcances del engaño típico. La apariencia inicial se desvanece, sin embargo, luego de un examen más detenido.

Si bien el carácter perjudicial del ejercicio de la libertad del autor no es razón suficiente para excluirla de la ponderación entre los intereses contrapuestos en la estafa, sí al menos debiera reconocerse que para que dicha libertad pueda prevalecer al cabo de la ponderación es indispensable que la restricción de la misma que supone el tipo penal resulte excesiva, lo que de ningún modo parece ser el caso. Porque, en efecto, no se aprecia cómo, incluso ante un comportamiento gravemente negligente de la víctima, se puede hacer prevalecer la libertad del autor no ya de participar en el intercambio económico ni de perseguir el mayor lucro posible ni de aprovechar su posible superioridad informativa, sino simplemente de realizar conductas que, como ocurre con los engaños con consecuencias patrimoniales perjudiciales, manifiestamente no son de ninguna utilidad ni para la víctima ni para el funcionamiento del sistema económico en general y que se pueden omitir sin mayor esfuerzo ni compromiso de la propia actividad comercial. Así las cosas, que la prohibición de ese tipo de conductas en razón de su dañosidad implique una restricción insoportable y de ningún modo justificable de la libertad de acción -en este caso de una supuesta "habilidad negocial" - es cuando menos una exageración.

En este contexto son interesantes los resultados a que arriba en relación con la estafa Frisch, precisamente uno de los autores que más ha destacado el papel general de la ponderación en la determinación de la conducta típica de los tipos penales ${ }^{91}$. Su punto de partida es que, en general, no puede prohibirse una conducta por el simple hecho de que favorezca o haga posible una autolesión o autopuesta en peligro, aun inconsciente, precisamente porque implicaría una restricción desproporcionada de la libertad de acción del agente (y una relativa interdicción de la víctima autorresponsable $)^{92}$. Excepciones solo serían admisibles (a) cuando la prohibición penal en rigor no le arrebata libertad al sujeto, sea porque, bien entendida, la libertad no cubre la conducta específica, sea porque disposiciones extrapenales la limitan legítimamente, y la imposición de una pena parece idónea, necesaria y proporcionada; o (b) cuando lo justifiquen

\footnotetext{
90 Silva SÁNCHEZ (1999) pp. 105 y s. (énfasis en el original).

${ }^{91}$ FRISCH (1988) pp. 70 y ss.

92 FRISCH (1988) pp. 182 y s.
} 
razones especiales que tienen que ver con déficit relevantes de la capacidad y disposición de la víctima para velar por sus propios intereses ${ }^{93}$.

Hay buenas razones para pensar que este autor debería tratar la situación del engaño en la estafa en el primer grupo de casos (por la existencia de prohibiciones extrapenales del engaño en el tráfico económico), pero lo cierto es que se pronuncia expresamente sobre ello a propósito del segundo grupo, en particular como un caso de superioridad de conocimiento. Luego de postular la necesidad social de proteger la confianza de las personas en que otros no las inducirán a realizar conductas cuya específica peligrosidad ellas no han podido advertir ${ }^{94}$ y de señalar al mismo tiempo los límites inmanentes de dicha protección, destaca especialmente que esta cede en ciertos ámbitos en que se debe contar con el aprovechamiento (considerado adecuado) de una superioridad informativa, cual sería el caso precisamente de las transacciones patrimoniales. Pero aun en estos ámbitos se puede y se debe restringir la libertad de acción: "El límite comienza en estos ámbitos recién con acciones calificadas, con las cuales tampoco aquí se puede contar, porque su autorización ya no es necesaria para la conservación de la ventaja del que sabe y, por el contrario, afecta otros principios importantes", de lo que serían ejemplos indiscutibles, precisamente, el engaño expreso y el engaño concluyente en la estafa ${ }^{95}$. La conclusión se muestra coherente con las reflexiones del mismo autor en otros trabajos, en los que destaca que las conductas que solo pueden dañar a otros sin prestarles ningún tipo de utilidad, en las que por lo mismo los potenciales afectados no tienen ningún interés, se encuentran por lo general (correctamente) desaprobadas ${ }^{96}$.

Las ideas de Frisch y sus consecuencias para la dogmática de la estafa han sido luego desarrolladas en detalle por Petra Wittig, quien también resuelve la ponderación en contra de la libertad de acción del agente en razón de que en todas las variantes reconocidas de engaño a la víctima se le ha relevado de la preocupación por el nivel informativo necesario para el cuidado de su patrimonio ${ }^{97}$.

En síntesis, tampoco desde esta perspectiva parece haber razones que justifiquen una restricción de los alcances del tipo de estafa. Queda abierto, por cierto, el campo de la discusión estrictamente política, expurgado ahora de aparentes argumentos de autoridad dogmática.

\section{UN ARGUMENTO NORMATIVISTA CONTRA EL ENGAÑO CALIFICADO}

Sin pretender invertir el punto de partida, cabe llamar la atención en cuanto a que las razones fundamentales que subyacen a la tendencia creciente de normativización de los conceptos jurídico-penales constituyen más bien un importante argumento en favor

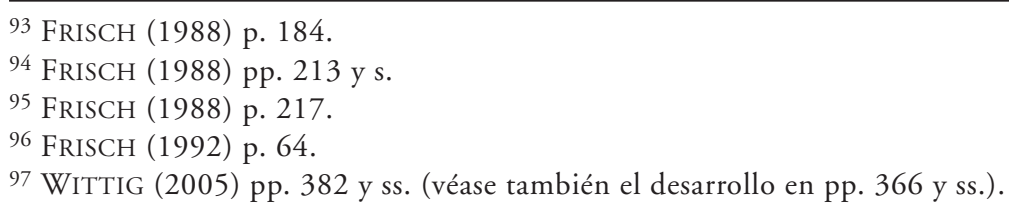


de la suficiencia de un engaño simple, no calificado, como engaño típico en los términos de la estafa.

Si es efectivo que la dogmática penal debe orientarse a la función social del Derecho penal y más específicamente, como se sostiene principalmente a partir de los desarrollos de Jakobs, si los conceptos fundamentales del Derecho penal deben corresponder a la estructura normativa de la sociedad, estructura mutable en razón de las circunstancias históricas y sociales, entonces la dogmática penal en el contexto actual debería estar en condiciones de ofrecer unos conceptos acordes con la estructura de sociedades funcionalmente diferenciadas, caracterizadas no solo por una intensa división del trabajo, sino que especialmente por el predominio de contactos sociales anónimos, estandarizados y orientados a roles ${ }^{98}$. En materia de estafa esto lo reconocen al menos en principio quienes se han ocupado del delito desde un punto de vista normativista. Así, por ejemplo, Pawlik desprende precisamente de las actuales condiciones sociales del intercambio económico que para la estafa solo deberían ser relevantes relaciones informativas típicas conforme a roles y las competencias vinculadas a ellas ${ }^{99}$, en tanto que Pastor Muñoz declara enfáticamente que los alcances del engaño típico deben extraerse de la "estructura normativa del mercado" 100 .

La cuestión ahora es si se aviene con esa función la mantención de un concepto altamente restrictivo de engaño, que impone a la potencial víctima que interviene en el mercado prácticamente el deber de desconfiar por principio de su contraparte a través de la imposición de "deberes de autoprotección". Es decir, precisamente en un contexto de contactos anónimos y estandarizados con pocos mecanismos de orientación se cierra precisamente la posibilidad eficiente y sin duda razonable de poder confiar por principio en el otro, posibilitando transacciones más expeditas y baratas. Y habrá de convenirse que desde esta perspectiva todo parece indicar que lo que vienen exigiendo los partidarios de un engaño calificado se va tornando crecientemente disfuncional ${ }^{101}$.

Esta forma de argumentar se ha ido extendiendo notoriamente en la dogmática alemana en materia de estafa. Así, por ejemplo, Frisch ha destacado recientemente a propósito de los alcances del engaño expreso y del engaño concluyente que no solo va en interés de las partes sino de la colectividad en su conjunto que en las transacciones económicas se pueda prescindir de declaraciones, preguntas, verificaciones y controles que resultan absurdos $-\mathrm{y}$ a veces hasta agraviantes- cuando versan sobre elementos que se desprenden naturalmente del tipo de negocio ${ }^{102}$ o bien cuando un actor en el tráfico económico declara ciertas circunstancias con la pretensión de que terceros conecten a

\footnotetext{
${ }^{98}$ JAKOBS (1996 b) p. 15; JAKOBS (1996 a) pp. 17 y ss., 45 y ss., 48; JAKOBS (2004) pp. 33 y ss.

99 PAWLIK (1999) pp. 148 y ss.

100 PASTOR MuÑoz (2004) pp. 212 y ss.

101 Es este especial contexto social el que le quita mucho de su fuerza a la aguda crítica de NAUCKE (1974) pp. 114 y ss., en cuanto a que la suficiencia para la estafa de un engaño no calificado favorecería un modelo de organización social que libera a los sujetos de la responsabilidad por el cuidado de su patrimonio y que, consecuentemente, genera dependencia y comodidad, a la vez que pretende suplir con penas los déficit de educación de la población.

102 FrISCH (2007) p. 106. Anunciado ya en FRISCH (1988) pp. 213 y s.
} 
ellas sus decisiones económicas ${ }^{103}$. Por su parte, en lo que se refiere al tratamiento de la duda de la víctima como error típico en la estafa, también se ha hecho presente que precisamente las modernas condiciones del intercambio económico obligan a los intervinientes a confiar y a contratar a pesar de sus dudas puntuales, de modo que un derecho penal que lo desconociera solo podría ser disfuncional ${ }^{104}$. Y en términos más generales, otros autores han destacado que, no obstante la legitimidad del lucro a costa de los otros y del aprovechamiento de la posible superioridad informativa, el aseguramiento de un mínimo de confianza en la veracidad de las informaciones provistas por otras personas constituye un presupuesto irrenunciable de la moderna economía de mercado ${ }^{105}$.

También en la literatura española se ha tenido que reconocer el carácter disfuncional que especialmente en las actuales condiciones del mercado tendría un modelo de interacciones económicas basado en la desconfianza, si bien no parecen haberse extraído todas las consecuencias que sugiere dicho reconocimiento. Así, por ejemplo, Pastor Muñoz hace presente que

"si se exigiera al disponente que realizara ese esfuerzo [informativo] ilimitado se rompería el mercado tal como está configurado hoy, pues la interacción se haría demasiado costosa. En efecto, si se pretende que el tráfico económico mantenga su estructura actual con las notas de anonimato y agilidad que le son propias, no se debe exigir de los sujetos que comprueben personalmente cada una de las informaciones en que basan sus decisiones de disposición" ${ }^{106}$.

\section{Y agrega:}

"En efecto, en una sociedad pequeña, el engaño y el error no tienen ninguna posibilidad de prosperar, porque cada uno conoce todo y conoce a todos y apenas hay roles definidos; en cambio, en un mercado complejo, surge la necesidad de confiar y, con ello, la posibilidad del engaño"107.

"En este sentido, es necesaria una garantía normativa de un mínimo de veracidad, de modo que los operadores económicos puedan confiar, con el respaldo del Derecho, en que los demás serán en cierta medida veraces. Lo cierto es que, sin esa garantía normativa, difícilmente puede mantenerse la interacción, pues si las alternativas que se le ofrecen al sujeto son, o bien averiguar por sí mismo las informaciones en que basa su decisión de disposición, o bien asumir todos los riesgos de error, la interacción se convierte en algo demasiado costoso y, entonces, lo más razonable es, quizá, renunciar a ella. En efecto, la absolutización de la desconfianza en las afirmaciones de los demás - esto, el tener que contar siempre

\footnotetext{
103 FrisCH (2007) pp. 103 y s.; WiTTIG (2005) pp. 382 y ss.

${ }^{104}$ HillenKamp (1981) p. 28; WitTMANN (2006) pp. 40 y s.

105 PAWLIK (1999) pp. 71 y s. También JAKOBS hace presente que si la única forma de reducir los riesgos en el tráfico económico fuera no hacer caso de las declaraciones de los otros se estaría condenado a una vida eremítica (JAKOBS [1999] p. 12).

106 PASTOR MUÑOZ (2004) p. 207.

107 PASTOR MuÑoz (2004) p. 209.
} 
con la posibilidad de que los demás sean unos mentirosos- es un principio incompatible con la existencia del tráfico económico"108.

"Por ello, la necesidad de confiar en las informaciones proporcionadas por otros está en las bases de la existencia del tráfico económico" ${ }^{109}$.

Es notorio, sin embargo, que estas reflexiones no juegan luego un papel particularmente relevante en la configuración del sistema de deberes de veracidad propuesto por la autora, quien parece tomarse al pie de la letra aquello de que se trata solo de una garantía "mínima”, de modo que se limita a reconocer deberes de veracidad ahí donde su negación simplemente haría ilusorio un tipo penal de estafa ${ }^{110}$. El punto de partida es la desconfianza, una garantía de confianza es excepcional y está fundada solo en la inexigibilidad general de verificación por parte del tipo de víctima, porque accesibilidad es, en último término, exigibilidad $^{111}$. El énfasis específico no se deriva entonces realmente de la estructura del mercado o de las condiciones de su funcionamiento, sino exclusivamente del dogma -no fundado en aquellas- de la existencia de deberes de autoprotección de la víctima.

Algo similar ocurre con Dopico Gómez-Aller, quien, no obstante destacar que si cada negociante "tuviese que informarse él solo sobre todos los extremos relevantes del negocio, se dispararían los costes de negociación para obtener una información de la que ya dispone el mercado (jla tiene uno de los negociantes!...) y la actividad económica sería inviable", y concluir luego que "(l)os deberes de veracidad e información, pues, se establecen para organizar una negociación sencilla y no dañosa para las partes" ${ }^{112}$, termina, sin embargo, extrayendo como única conclusión la necesidad de establecer niveles diferenciados de cuidado exigible a la víctima, distinguiendo fundamentalmente entre consumidores a quienes se les debe exigir menos y agentes económicos profesionales a quienes se debe exigir lo habitual, es decir, mucho ${ }^{113}$. Y esto, en rigor, con fundamento en la protección debida al consumidor (consagrada con rango constitucional en el derecho español) ${ }^{114}$ y en ningún caso en la estructura del mercado. Más aún, el autor es explícito en cuanto a que solo se trata de una excepción al principio general de autorresponsabilidad (y a la idea de deberes

\footnotetext{
108 PASTOR MUÑOZ (2004) pp. 209 y s.

109 PASTOR MUÑoz (2004) p. 209, y en general sobre todo esto, pp. 207 y ss.

110 PASTOR MuÑoz (2004) pp. 225 y ss.

111 A primera vista este punto de partida parece coincidir con el de Pawlik, quien también reconoce que en la vida económica se recomienda una cierta dosis de desconfianza y parece oponerse solo a la absolutización de la misma (PAWLiK [1999] p. 71). Cuando lo hace, sin embargo, el autor alemán simplemente está constatando el carácter de bien escaso de la información y la legitimidad general de su aprovechamiento con ánimo de lucro como condiciones de partida de las interacciones económicas, pero a la hora de analizar estas últimas y definir el "mínimo" de confianza que debe ser garantizado no duda en identificarlo con el respeto de los mecanismos de interacción (comunicación) reconocidos cuyo buen funcionamiento resulta socialmente irrenunciable para la transmisión interpersonal de información y, con ello, para la posibilidad de reducir el cúmulo de información disponible en una sociedad moderna a niveles individualmente manejables y a costos razonables (pp. 162 y s.). La garantía no se funda, en consecuencia, en lo que sea exigible a la víctima conforme a su rol, sino en el mecanismo de interacción empleado.

112 Dopico Gómez-Aller (2006 a) p. 6 (énfasis en el original). En los mismos términos Dopico GÓMEZ-AlLER (2006 b) p. 145, si bien en este último lugar en un contexto poco inteligible.

113 DOPico GÓmeZ-Aller (2006 a) p. 4 y passim.

114 Dopico GómeZ-Aller (2006 a) pp. 4 y s.
} 
de autoprotección) como límite del tipo de estafa ${ }^{115}$ y en todo caso excluye de la excepción las hipótesis de llamado dolo bueno y de las afirmaciones absurdas (entre ellas la oferta de ventajas disparatadamente superiores a las esperables en el mercado) ${ }^{116}$.

En cambio, las cosas son algo distintas con Piña, quien mejor ha expresado en Chile la necesidad social de una garantía de confianza con efectos para la estafa. Luego de destacar el carácter irrenunciable de la confianza para la interacción social ${ }^{117}$, Piña invierte el sentido tradicional del principio de confianza para enjuiciar no ya la conducta del autor, sino la de la víctima del engaño, en los siguientes términos:

"De este modo, no es exigible a quienes participan de la vida en comunidad que circulen verificando a cada momento que lo que se les dice es verdad... Si se exigiera un cuidado de esa naturaleza, nunca se podría imputar a terceros la defraudación porque siempre habría sido la víctima la que ha infringido sus deberes de auto-custodia.

En los ámbitos de interacción económica este principio probablemente cobra su máxima vigencia... En esta línea, podemos afirmar que quien opera en el ámbito económico no solo tiene la necesidad de confiar en informaciones que no han sido generadas por él (aportadas por terceros) sino que tiene el derecho a hacerlo. Es imposible para cada uno de los agentes de un determinado mercado tener acceso directo a muchas informaciones relevantes para su actividad económica, por ello es imprescindible que respecto de algunas de esas informaciones se pueda confiar en los datos que entreguen terceros" 118 .

Consecuentemente con esto y con una perspectiva funcionalista -si bien destaca al mismo tiempo la existencia de deberes de autoprotección que deriva del principio de autorresponsabilidad ${ }^{119}$ - Piña mantiene una posición mucho más neutral en lo que respecta a los deberes de veracidad, pues no asume como punto de partida la idea de accesibilidad $^{120}$, que pone a priori y como regla la carga sobre el disponente, sino que simplemente se somete a lo que resulte del examen sectorial de las regulaciones y prácticas propias de la operación de cada mercado en cuestión ${ }^{121}$. De este modo, no tiene dificultades en reconocer que en determinados mercados inveracidades muy sencillas puedan ser completamente suficientes para constituir engaño típico, con total independencia de que se hubieran podido descubrir con poco esfuerzo ${ }^{122}$. De ahí que, al margen

\footnotetext{
115 Dopico GómeZ-Aller (2006 a) p. 5.

116 DOPico GÓMEZ-Aller (2006 a) pp. 5 y ss.

117 PIÑA (2004) pp. 57 y ss.

118 PIÑA (2004) p. 59 (énfasis agregado).

119 PIÑA (2004) pp. 61 y s.

120 Sin perjuicio de que puntualmente sugiera otra cosa, por ejemplo, en la ya mencionada reformulación de la síntesis de Cancio.

121 PIÑA (2004) pp. 62 y ss.

122 PIÑA (2004) p. 64: "si en una determinada actividad se acepta de un modo convencional y general una mera declaración escrita como inventario de especies a embarcar, la falsedad contenida en esa declaración constituye engaño suficiente aun cuando la víctima hubiese podido salir fácilmente de él revisando las mercaderías embarcadas" (énfasis agregado).
} 
del tono general de sus reflexiones y la apariencia inicial, sea bastante dudoso que Piña realmente adscriba a la tesis restrictiva tradicional.

Del mismo modo, aunque en términos más ambiguos ${ }^{123}$, Mayer llama la atención sobre la tendencia legislativa -jespecialmente en el ámbito de las actividades económicas altamente profesionalizadas, como el de las bolsas de valores o los bancos!- a establecer importantes deberes de veracidad en favor de víctimas autorresponsables y parece aprobarla tácitamente ${ }^{124}$. La pregunta que cabría hacerse es si esta tendencia legislativa, a todas luces concordante con las condiciones de operación de mercados complejos, es realmente una novedad y una excepción o si, por el contrario, solo es concreción sectorial de principios generales de la regulación de la interacción económica. Aquí se está por lo segundo.

Como se ha dicho al comienzo de este trabajo, el nivel de protección de la víctima que debe prodigarse a través del tipo de estafa y específicamente a través de la interpretación del engaño típico es una decisión política respecto de la cual el método dogmático no tiene nada que decir directamente. Aquí se ha tratado de demostrar que, en efecto, la normativización de la estafa no sirve para validar exigencias de engaño calificado, y que, más bien al contrario, sus presupuestos sugieren la conveniencia de una prohibición amplia de conductas que defraudan una garantía igualmente amplia de confianza que permite contactos económicos anónimos eficientes. Y si bien no debe sobrestimarse el argumento, porque las razones que justifican una prohibición en esos términos y su respaldo penal se encuentran también y en abundancia en otros planos, al menos debe destacarse que es un argumento que merecería que los partidarios de la tesis restrictiva se hicieran cargo de él.

\section{EL VERDADERO SENTIDO RESTRICTIVO DE LA NORMATIVIZACIÓN DE LA ESTAFA}

Ahora bien, contra lo que pudiera creerse, con lo dicho hasta aquí de ningún modo se ha querido decir que la normativización de la dogmática de la estafa no tenga consecuencias relevantes para la delimitación de un injusto típico que, en efecto, tratándose de esta figura delictiva parece especialmente indispensable. Porque mal se podría legitimar un delito que simplemente consistiera en la causación de errores perjudiciales en virtud de cualquier tipo de mentiras, sin mayores precisiones, con riesgo cierto de desbordarse en cada momento. Y es precisamente Leitmotiv de las doctrinas de la imputación objetiva y, en general, de la dogmática de orientación normativista la fijación ex ante de los alcances de las prohibiciones y mandatos penales ${ }^{125}$.

\footnotetext{
123 Por su explícita apelación a autores como Pérez Manzano, Pastor Muñoz y Dopico Gómez-Aller, que en rigor llegan a las conclusiones opuestas.

124 MAYer (2008) pp. 390 y ss.

$125 \mathrm{Si}$ bien esto es menos nítido en la aplicación a la estafa del modelo más tradicional de la imputación objetiva del resultado, también en ese contexto debe precisarse ex ante cuando el riesgo creado por la conducta es un riesgo "prohibido" en el sentido del tipo de estafa.
} 
La crítica precedente a la opinión restrictiva tradicional en materia de estafa no se dirige entonces a sus propósitos de delimitación y consiguiente restricción, sino simplemente al empleo al menos tácito de la normativización como argumento en favor de conclusiones para las cuales esta en realidad no ofrece sustento. Porque la delimitación que fluye de la perspectiva normativista tiene que ver con la definición de esferas de competencia y deberes asociados a las mismas y no con un supuesto déficit de merecimiento de protección de víctimas crédulas, torpes o negligentes.

Y esto no solo por los inconvenientes políticos de esta última perspectiva, sino también y especialmente porque se advierte poco idónea para una adecuada delimitación de la conducta prohibida, por su carácter variable y azaroso. En efecto, en la medida en que la definición de lo que una víctima concreta en un caso determinado puede creer sin ser considerada crédula, torpe o negligente depende de un cúmulo incontrolable de circunstancias, esta posición difícilmente está en condiciones, más allá de ciertos casos paradigmáticos, de superar el estadio de una orientación general vaga e insegura ${ }^{126}$.

Por el contrario, más allá del posible desacierto terminológico, el recurso a los llamados deberes de veracidad como presupuesto del engaño típico enfatiza el punto de partida fundamental, cual es que solo de un modo excepcional -justamente cuando se tiene un deber de veracidad a su respecto- se es competente y responsable por los errores o vacíos informativos que puedan afectar a otros en la interacción económica, incluso de aquellos que uno mismo ha causado. Lo relevante no es entonces la simple causación de un error, sino la infracción de un deber preciso de evitarlo, esto es, la infracción de un preciso deber de veracidad ${ }^{127}$.

Así, por regla generalísima quien interviene en el tráfico económico no está obligado a velar porque su contraparte tome las mejores decisiones en base a la mayor y mejor información posible -lo que en rigor es asunto exclusivamente de ella -, de modo que si no evita que esta se equivoque no le puede caber responsabilidad en ello, aunque hubiera estado en condiciones de hacerlo sin mayor esfuerzo e incluso aunque actúe con deliberada mala fe. Esta situación solo cambia cuando excepcionalmente el sujeto ha asumido o se le ha impuesto por razones institucionales esa competencia, que por regla general se expresará en la asunción o imposición de deberes de información. En esto, como se puede ver, la doctrina del engaño como infracción de un deber de veracidad conduce a resultados tan restrictivos como los de la postura tradicional.

Las diferencias con dicha postura tradicional se concentran en aquellos casos en los que el error o vacío de información ha sido provocado por la conducta del sujeto.

126 En el mismo sentido la crítica de KINDHÄUSER (1991) pp. 405 y s. a la propuesta de solución de Naucke (preferencia de la causalidad adecuada por sobre la equivalencia de las condiciones), haciendo presente, además, que en el caso estándar de estafa el autor configura su engaño a partir de las peculiaridades de la víctima y sus circunstancias.

127 En efecto, la definición del engaño como infracción de un deber de veracidad sirve también a ese fin y no solo a la provisión de una base conceptual común para todas las formas de engaño que permite superar la convivencia tradicional de justificaciones heterogéneas y hasta potencialmente contradictorias de las formas de engaño reconocidas (causación del error tratándose del engaño expreso, infracción de un deber de información en el caso del engaño por omisión, mezcla confusa de ambos principios en el engaño concluyente); sobre esto último PAWLIK (1999) pp. 142 y ss.; FRISCH (2007) pp. 120 y ss.; FRISCH (2008) pp. 729 y ss. 
Nótese, sin embargo, que también en estos casos la doctrina de los deberes de veracidad impone límites a la consideración de un engaño típico, porque, como se ha dicho, lo decisivo no es la simple causación (aun dolosa) de un error, sino la infracción de un deber de veracidad para con el otro. Así, no engaña en los términos de la estafa aquel que miente en un contexto no negocial (por ejemplo, al cometer falso testimonio; o en general, respecto de quien no es destinatario de las declaraciones) o quien lo hace en un contexto de ese tipo pero respecto de aspectos irrelevantes para la transacción, por no constituir objeto ni natural ni accidental del intercambio en cuestión (por ejemplo, cuando se indica mendazmente que el objeto es el último que se encuentra disponible o que se ha recibido una determinada oferta).

La cuestión crucial es, sin embargo, el sentido y valor que para estos efectos debe dársele a los casos en que se entrega información relevante para el negocio en un contexto efectivamente negocial o, para decirlo con otras palabras, el sentido y valor de la intervención de los sujetos en el tráfico económico empleando los códigos reconocidos para las interacciones en el mismo, lo que implica la pretensión de ser reconocido como interlocutor válido y contraparte (en definitiva: ¡la pretensión de ser tomado en serio!) en una negociación económica.

Este es el verdadero punto de quiebre entre los desarrollos de las tesis del engaño como infracción de un deber de veracidad en su país de origen y en nuestro medio. Mientras que en Alemania no se tienen dudas en cuanto a que dicha intervención y especialmente la pretensión que implica es fuente más que suficiente de deberes de veracidad para con la contraparte, en el sentido de una garantía de corrección de la información a la que se pretende que esta asocie sus disposiciones patrimoniales, en España y entre nosotros, en cambio, este dato fundamental parece no tener mayores consecuencias jurídicas y queda oculto bajo la afirmación de importantes deberes de autoprotección del destinatario de la información potencialmente falsa.

Cuál de ambas posiciones debe preferirse es, en último término, una cuestión política respecto de la cual, como se ha insistido, el normativismo se comporta de modo más bien neutral. Procurar demostrar esto último ha sido el objetivo preciso de este trabajo, objetivo modesto pero indispensable para continuar la discusión en torno a los alcances del engaño típico en la estafa sin la interferencia de argumentos aparentes e inductivos a error.

En todo caso, como es obvio, aquí se favorece la primera posición y se prefiere una delimitación del engaño típico que opera erga omnes y sobre una base objetiva, como es la relevancia negocial tanto de la situación comunicativa como de la información entregada, con total independencia de la inteligencia, prudencia o escepticismo del destinatario de la misma ${ }^{128}$. Desde luego esto no se opone al posible reconocimiento de ciertos "deberes de autoprotección" emanados de las regulaciones sectoriales de la actividad económica en cuestión, los que, sin embargo, tienen en este contexto un trasfondo y un significado totalmente diferente al pretendido por la opinión restrictiva dominante.

${ }^{128}$ En palabras de KINDHÄUSER (1991) p. 406: "una solución justa y equilibrada conforme a criterios realmente normativos". 
Se impone ahora la tarea de desarrollar con más precisión los criterios de relevancia a ser aplicados, tarea que, sin embargo, deberá abordarse con detalle en otro lugar.

\section{BIBLIOGRAFÍA CITADA}

Amelung, Knut (1977): "Irrtum und Zweifel des Getäuschten beim Betrug", GA 1977, pp. 1 y ss.

ARroyo DE LAS Heras, Alfonso (2005): Los delitos de estafa y falsedad documental, (Barcelona, Bosch).

Bajo Fernández, Miguel (2004): Los delitos de estafa en el Código penal (Madrid, Editorial Universitaria Ramón Areces).

Bullemore, Vivian; MaCKinnon, John (2005): Curso de derecho penal, T. III (Santiago, LexisNexis).

CANCIO Meliá, Manuel (1993): "La teoría de la adecuación social en Welzel”, ADPCP 1993, pp. 697 y ss.

CANCIO Meliá, Manuel (1998): Conducta de la víctima e imputación objetiva en Derecho penal (Barcelona, J.M. Bosch).

CANCiO Meliá, Manuel (2003): "Conducta de la víctima y responsabilidad jurídicopenal del autor”, en: REYNA ALFARO, Luis (director), Derecho, proceso penal y victimología (Mendoza, Ediciones Jurídicas Cuyo).

Cousiño, Luis (1979): Derecho penal chileno, T. II (Santiago, Editorial Jurídica de Chile).

Choclán Montalvo, José Antonio (1999): "Engaño bastante y deberes de autoprotección", Revista de Derecho y Proceso Penal, No 2 (1999), 59.

Choclán Montalvo, José Antonio (2000): El delito de estafa (Barcelona, Bosch).

De Francesco, Gennaro; Zanchetti, Mario (1999): “Art. 640”, en: Crespi, Alberto;

Stella, Federico; ZuCCAlÀ, Giuseppe (direttori), Commentario breve al Codice penale (Padova, CEDAM, seconda edizione).

DolCInI, Emilio; MARINUCCI, Giorgio (2006): Codice penale commentato. Parte speciale (Assago [Milano], IPSOA, seconda edizione).

Dopico GÓmEZ-Aller, Jacobo (2006 a): "La estafa sobre datos registrales", InDret 3/ 2006.

Dopico GÓmeZ-Aller, Jacobo (2006 b): "Los delitos de estafa en el tráfico inmobiliario”, en: POZuelo PÉREZ, Laura (coordinadora), Derecho penal de la construcción (Granada, Comares).

ELLMER, Manfred (1986): Betrug und Opfermitverantwortung (Berlin, Duncker \& Humblot).

ETCHEBERry, Alfredo (1998): Derecho penal, T. III (Santiago, Editorial Jurídica de Chile, $3^{\text {a }}$ edición).

FERnÁNDEZ, Álvaro (2005): "Engaño y víctima en la estafa”, Revista de Derecho de la Pontificia Universidad Católica de Valparaíso, T. XXVI (2005-I), pp. 181 y ss.

FRISCH, Wolfgang (1979): "Funktion und Inhalt des 'Irrtums' im Betrugstatbestand", en: Kaufmann, Arthur et al. (Hrsg.), Festschrift für Paul Bockelmann (München, Beck). 
FRISCH, Wolfgang (1988): Tatbestandsmäbiges Verhalten und Zurechnung des Erfolgs, (Heidelberg, C.F. Müller).

FRISCH, Wolfgang (1992): "Selbstgefährdung im Strafrecht”, NStZ 1992, pp. 1 y ss., 62 y ss.

FRISCH, Wolfgang (2007): “Konkludentes Täuschen”, en: PAWLIK, Michael; ZACZYK, Rainer (Hrsg.), Festschrift für Günther Jakobs (Köln etc., Heymanns).

FRISCH, Wolfgang (2008): "Grundfragen der Täuschung und des Irrtums beim Betrug", en: PutzKe, Holm et al. (Hrsg.): Strafrecht zwischen System und Telos. Festschrift für Rolf Dietrich Herzberg (Tübingen, Mohr Siebeck).

Gallego Soler, José Ignacio (2005): "Fundamento y límites de los deberes de autoprotección de la víctima en la estafa (comentario de jurisprudencia)”, ADPCP 2005, pp. 529 y ss.

GALlego Soler, José Ignacio (2008): "Una visión general de los delitos defraudatorios contra el patrimonio en el derecho penal español: teoría y praxis”, en: SERRANOPiedecasas, José Ramón; Demetrio Crespo, Eduardo (directores), Cuestiones actuales de derecho penal económico (Madrid, Colex).

Garrido, Mario (2000): Derecho penal, T. IV (Santiago, Editorial Jurídica de Chile).

Gómez BeníteZ, José Manuel (1985): "Función y contenido del error en el tipo de estafa", ADPCP 1985, pp. 333 y ss.

HASSEMER, Raimund (1981): Schutzbedürftigkeit des Opfers und Strafrechtsdogmatik (Berlin, Duncker \& Humblot).

Hennings, Frank (2002): Teleologische Reduktion des Betrugstatbestandes aufgrund von Mitverantwortung des Opfers (Berlin, Duncker \& Humblot).

HERnÁNDEZ, Héctor (2003): "Aproximación a la problemática de la estafa”, en: AA. VV., Problemas actuales de derecho penal (Temuco, Universidad Católica de Temuco).

HERNÁNDEZ, Héctor (2008 a): "Täuschung und Opferschutzniveau beim Betrug - zwischen Kriminalpolitik und Dogmatik", en: SIEBER, Ulrich et al. (Hrsg.): Festschrift für Klaus Tiedemann (Köln etc., Heymanns).

HeRnÁNDEZ, Héctor (2008 b): "Frustración de fines y perjuicio patrimonial en el derecho penal chileno”, en: FERNÁNDEZ, José Ángel (coordinador), Estudios de ciencias penales (Santiago, LegalPublishing).

HilgendorF, Eric (1998): Tatsachenaussagen und Werturteile im Strafrecht (Berlin, Duncker \& Humblot).

HillenKamp, Thomas (1981): Vorsatzsatz und Opferverhalten (Göttingen, Schwartz).

HRUSCHKA, Joachim (2005): "Reglas de comportamiento y reglas de imputación" (Trad. BALdÓ LAVILla), en: HruschKA, Joachim: Imputación y Derecho penal. Estudios sobre la teoría de la imputación (edición a cargo de Pablo Sánchez-Ostiz, Cizur Menor, Thomson-Aranzadi).

JAKOBS, Günther (1986): "Nötigung durch Gewalt", en: HIRSCH, Hans-Joachim et al. (Hrsg.), Gedächtnisschrift für Hilde Kaufmann (Berlin - New York, De Gruyter).

JAKOBS, Günther (1991): Strafrecht AT (Berlin - New York, De Gruyter, 2. Aufl.).

JAKOBS, Günther (1996 a): La imputación objetiva en derecho penal (Trad. CANCIO Meliá, Buenos Aires, Ad-Hoc). 
JAKOBS, Günther (1996 b): Sociedad, norma y persona en una teoria de un derecho penal funcional (Trad. CANCIO MELIÁ; FEIJÓO SÁNCHEZ, Madrid, Civitas).

JAKOBS, Günther (1999): Urkundenfälschung. Revision eines Täuschungsdelikts (Köln etc., Heymanns).

JAKOBS, Günther (2004): "La ciencia del derecho penal ante las exigencias del presente" (Trad. MANSO PORTO), en: JAKOBS, Günther: Dogmática del derecho penal y la configuración normativa de la sociedad (Madrid, Thomson-Civitas).

KINDHÄUSER, Urs (1991): “Täuschung und Wahrheitsanspruch beim Betrug”, ZStW 103, pp. 398 y ss.

KINDHÄUSER, Urs (1997): "Betrug als vertypte mittelbare Täterschaft", en: SCHUlZ, Joachim; Vormbaum, Thomas (Hrsg.), Festschrift für Günter Bemmann (Baden-Baden, Nomos).

KINDHÄUSER, Urs (2005): “\$ 263”, en: KINDHÄUSER, Urs et al. (Hrsg.), Nomos-Kommentar zum Strafgesetzbuch (NK) (Baden-Baden, Nomos 2. Aufl.).

KuRTH, Frowin Jörg (1984): Das Mitverschulden des Opfers beim Betrug (Frankfurt a.M. etc., Peter Lang).

LabatuT, Gustavo (1983): Derecho penal, T. II (Santiago, Editorial Jurídica de Chile, $7^{\text {a }}$ edición a cargo de Julio Zenteno).

LaFave, Wayne R.; ScotT, Austin W. Jr. (1986): Criminal law (St. Paul, Minn., West 2nd edition).

Larguier, Jean; Conte, Philippe (2004): Droit pénal des affaires (Paris, Colin, 11e édition).

MAÑAliCH, Juan Pablo (2006): “El 'hurto-robo' frente a la autotutela y la legítima defensa de la posesión”, REJ, No 7 (2006), pp. 65 y ss.

Mayaud, Yves (2003): Code pénal (Paris, Dalloz, 100e édition).

MAYER, Laura (2008): "El actuar de la víctima en el delito de estafa. En especial sobre el principio de autoprotección y los deberes de veracidad”, en: RODRÍGUEZ COLLAO, Luis (coordinador), Delito, pena y proceso. Libro homenaje a la memoria del Prof. Tito Solari Peralta (Santiago, Editorial Jurídica de Chile).

MERA, Jorge (1986): Fraude civil y penal. El delito de entrega fraudulenta (Santiago, ConoSur, $2^{\mathrm{a}}$ edición).

NAMER, Sabrina (2002): Estafa e imputación objetiva (Buenos Aires, Ad-Hoc).

NÁQuira, Jaime (1998): Derecho penal. Teoría del delito I (Santiago, McGraw-Hill).

NAUCKE, Wolfgang (1964): Zur Lehre vom strafbaren Betrug (Berlin, Duncker \& Humblot).

NAUCKE, Wolfgang (1974): “Der Kausalzusammenhang zwischen Täuschung und Irrtum beim Betrug”, en: BAUMANN, Jürgen et al. (Hrsg.), Einheit und Vielfalt des Strafrechts. Festschrift für Karl Peters zum 70. Geburtstag (Tübingen, Mohr).

NAVARro CARDOSO, Fernando (1998): "Algunas consideraciones sobre las estafas colectivas a los consumidores", Poder Judicial, No 50 (1998), pp. 167 y ss.

NovoA, Eduardo (1960): Curso de derecho penal chileno, T. I (Santiago, Editorial Jurídica de Chile).

PAstor Muñoz, Nuria (2003 a): “Consideraciones sobre la delimitación del engaño 
típico en el delito de estafa", en: MONTEALEGRE, Eduardo (coordinador), El funcionalismo en derecho penal. Libro homenaje al Prof. Günther Jakobs, T. II (Bogotá, Universidad Externado de Colombia).

PASTOR MuÑoz, Nuria (2003 b): “El redescubrimiento de la responsabilidad de la víctima en la dogmática de la estafa”, en: SiLVA SÁnCHEZ, Jesús María (director), ¿Libertad económica o fraudes punibles? Riesgos penalmente relevantes e irrelevantes en la actividad económico-empresarial (Madrid - Barcelona, Marcial Pons).

Pastor Muñoz, Nuria (2004): La determinación del engaño típico en el delito de estafa (Madrid - Barcelona, Marcial Pons).

PAWliK, Michael (1999): Das unerlaubte Verhalten beim Betrug (Köln etc., Heymanns).

PEDraZzI, Cesare (1955): Inganno ed errore nei delitti contro il patrimonio (Milano, Giuffrè).

PÉREZ MANZANO, Mercedes (1995): “Acerca de la imputación objetiva en la estafa”, en: AA. VV., Hacia un Derecho penal económico europeo. Jornadas en honor del Prof. Klaus Tiedemann (Madrid, BOE).

PIÑA, Juan Ignacio (2004): Fraude de seguros (Santiago, Universidad de los Andes).

Politoff, Sergio; Matus, Jean Pierre; Ramírez, María Cecilia (2005): Lecciones de derecho penal chileno. Parte especial (Santiago, Editorial Jurídica de Chile, 2a edición).

Roxin, Claus (1976): "Sobre el fin de protección de la norma en los delitos imprudentes” (Trad. Luzón PeÑA), en: RoXin, Claus: Problemas básicos del derecho penal (Madrid, Reus).

RoxIN, Claus (2003): Strafrecht AT II (München, Beck).

RoXIN, Claus (2006 a): Strafrecht AT I (München, Beck, 4. Aufl.).

Roxin, Claus (2006 b): Täterschaft und Tatherrschaft (Berlin - New York, De Gruyter, 8. Aufl.).

SCHLÜCHTER, Ellen (1994): “Tatbestandsmerkmal des Vermögensschadens beim Betrug - Ärgernis oder Rechtsstaatserfordernis?”, en: BRIESKORN, Norbert (Hrsg.), Vom mittelalterlichen Recht zur neuzeitlichen Rechtswissenschaft (Festschrift für Winfried Trusen) (Paderborn etc., Schöningh).

SCHUMANN, Heribert (1986): Strafrechtliches Handlungsunrecht und das Prinzip der Selbstverantwortung der Anderen (Tübingen, Mohr [Paul Siebeck]).

SCHÜNEMANN, Bernd (1978): "Der strafrechtliche Schutz der Privatsphäre", ZStW 90 (1978), pp. 11 y ss.

SCHÜnemann, Bernd (1979): "Methodologische Prolegomena zur Rechtsfindung im Besonderen Teil des Strafrechts”, en: Kaufmann, Arthur et al. (Hrsg.), Festschrift für Paul Bockelmann (München, Beck).

SCHÜNEMANN, Bernd (1986): "Zur Stellung des Opfers im System der Strafrechtspflege (II)”, NStZ 1986, pp. 439 y ss.

SCHÜNEMANN, Bernd (2000): “Vor $\$ 201 ”, “ \$ 201 ”, “ \$ 202 ”, “ \$ 202$ a”, “\$203”, en: JÄHNKE, Burkhard et al. (Hrsg.), Leipziger Kommentar zum Strafgesetzbuch (LK) (Berlin - New York, De Gruyter, 11. Aufl.).

SCHÜNEMANN, Bernd (2002): "Das System des strafrechtlichen Unrechts: Rechtsgutsbegriff und Viktimodogmatik als Brücke zwischen dem System des Allgemeinen Teils 
und dem Besonderen Teil”, en: Schünemann, Bernd (Hrsg.), Strafrechtssystem und Betrug (Herbolzheim, Centaurus).

SILVA SÁNCHEZ, Jesús María (1989): “¿Consideraciones victimológicas en la teoría jurídica del delito? Introducción al debate sobre la victimodogmática”, en: DE LA CUESTA, José Luis et al. (compiladores), Criminología y derecho penal al servicio de la persona. Libro-Homenaje al Prof. Antonio Beristain (San Sebastián, Instituto Vasco de Criminología).

Silva SÁnCHEZ, Jesús María (1999): "Las inveracidades de los particulares ante el Derecho penal”, en: SAlvador Coderch, Pablo; Silva SÁnCHeZ, Jesús María: Simulación y deberes de veracidad. Derecho civil y Derecho penal: dos estudios de dogmática jurídica (Madrid, Civitas).

Silva SÁNCHEZ, Jesús María (2003): “Introducción”, en: SilVA SÁNCHEZ, Jesús María (director), ¿Libertad económica o fraudes punibles? Riesgos penalmente relevantes e irrelevantes en la actividad económico-empresarial (Madrid - Barcelona, Marcial Pons).

Simester, A. P.; Sullivan, G. R. (2003): Criminal law (Oxford etc., Hart, 2nd edition).

TiedemanN, Klaus (2000): “Vor $₫$ 263”, “\$ 263”, en: JÄHNKE, Burkhard et al. (Hrsg.), Leipziger Kommentar zum Strafgesetzbuch (LK) (Berlin - New York, De Gruyter, 11. Aufl.).

Timpe, Gerhard (1989): Die Nötigung (Berlin, Duncker \& Humblot).

TORÍO LÓPEZ, Ángel (1982): “Acción y resultado típico en la estafa procesal”, en: AA. VV., Estudios penales. Libro Homenaje al Prof. J. Antón Oneca (Salamanca, Ediciones Universidad de Salamanca).

VAlle Muñiz, José Manuel (1987): El delito de estafa (Barcelona, Bosch).

VOGEL, Joachim (2003): "Betrug durch konkludente Täuschung: 'Recht auf Wahrheit' oder kommunikative Verkehrssicherungspflichten?”, en: AA. VV., Gedächtnisschrift für Rolf Keller (Tübingen, Mohr Siebeck).

Wagemann, Christian (2005): Die Geschichte des Betrugsstrafrechts in England und den amerikanischen Bundesstaaten (Herbolzheim, Centaurus).

WALTER, Tonio (1999): Betrugsstrafrecht in Frankreich und Deutschland (Heidelberg, C.F. Müller).

Welzel, Hans (1975): "Studien zum System des Strafrechts", en: WelZEL, Hans, Abhandlungen zum Strafrecht und zur Rechtsphilosophie (Berlin - New York, De Gruyter).

WiTTIG, Petra (2005): Das tatbestandsmäbige Verhalten des Betrugs (Frankfurt a.M., Vittorio Klostermann).

WitTmann, Christian (2006): Wissenszurechnung im Strafrecht (Berlin, Duncker \& Humblot). Yubero, Julio (1993): El engaño en el delito de estafa (Santiago, ConoSur). 
